\title{
The evolution of dopamine systems in chordates
}

\author{
Kei Yamamoto and Philippe Vernier* \\ Neurobiology and Development (UPR3294), Institute of Neurobiology Alfred Fessard, CNRS, Gif-sur-Yvette, France
}

\section{Edited by:}

Agustín González, Universidad

Complutense de Madrid, Spain

\section{Reviewed by:}

Mario F. Wullimann, Ludwig

Maximilians University, Germany

Nilima Prakash, Helmholtz Center

Munich, Germany

*Correspondence:

Philippe Vernier, Neurobiology and Development (UPR3294), Institute of Neurobiology Alfred Fessard, CNRS, Gif-sur-Yvette 91198, France.

e-mail: vernier@inaf.cnrs-gif.fr
Dopamine (DA) neurotransmission in the central nervous system (CNS) is found throughout chordates, and its emergence predates the divergence of chordates. Many of the molecular components of DA systems, such as biosynthetic enzymes, transporters, and receptors, are shared with those of other monoamine systems, suggesting the common origin of these systems. In the mammalian CNS, the DA neurotransmitter systems are diversified and serve for visual and olfactory perception, sensory-motor programming, motivation, memory, emotion, and endocrine regulations. Some of the functions are conserved among different vertebrate groups, while others are not, and this is reflected in the anatomical aspects of DA systems in the forebrain and midbrain. Recent findings concerning a second tyrosine hydroxylase gene (TH2) revealed new populations of DA-synthesizing cells, as evidenced in the periventricular hypothalamic zones of teleost fish. It is likely that the ancestor of vertebrates possessed TH2 DA-synthesizing cells, and the TH2 gene has been lost secondarily in placental mammals. All the vertebrates possess DA cells in the olfactory bulb, retina, and in the diencephalon. Midbrain DA cells are abundant in amniotes while absent in some groups, e.g., teleosts. Studies of protochordate DA cells suggest that the diencephalic DA cells were present before the divergence of the chordate lineage. In contrast, the midbrain cell populations have probably emerged in the vertebrate lineage following the development of the midbrain-hindbrain boundary. The functional flexibility of the DA systems, and the evolvability provided by duplication of the corresponding genes permitted a large diversification of these systems. These features were instrumental in the adaptation of brain functions to the very variable way of life of vertebrates.

Keywords: tyrosine hydroxylase, monoamine transporters, monoamine receptors, vertebrates, protochordates, gene duplication, forebrain, hypothalamus

\section{INTRODUCTION}

Since the seminal discovery that it could be a neurotransmitter in the central nervous system (CNS) of vertebrates (Carlsson et al., 1958), dopamine (DA) has received a lot of attention due to its role in many cerebral functions and its implication in a number of major human diseases. Indeed, DA acts to modulate early steps of sensory perception in the olfactory bulb and the retina, motor programming, learning, and memory, affective and motivational processes in the forebrain, control of body temperature, food intake, and several other hypothalamic functions as well as chemosensitivity in the area postrema and solitary tract, to cite only the main of the DA-controlled functions. Dysfunction of DA neurotransmission was initially shown in Parkinson's disease (Hornykiewicz, 1962), fostering an enormous interest for this neurotransmitter. In addition, DA has now been shown to significantly contribute to the pathophysiology of several psychiatric disorders such as schizophrenia, addiction to drugs, or attention deficit with hyperactivity.

Implication of DA in such a large range of otherwise unrelated functions, its wide distribution in a number of brain nuclei, and fast-growing knowledge about the differentiation of these DA neuronal groups strongly suggest that there is not a unique DA system, but several, independent anatomo-physiological systems, with DA as the only common denominator. It is thus of importance to trace back the origin of these different DA systems in the course of the evolution of chordate animals, the group to which vertebrates belong, in order to gain clues of the adaptive constraints which led to select each of the DA systems, and to understand better the nature of functions that DA exerts in the brain and how it can become maladaptive in neuropsychiatric diseases. In this review, we integrate recent data with established features of DA systems, to shed a new light on their origin and evolution in chordates.

\section{MOLECULAR COMPONENTS DEFINING THE PHENOTYPE OF DA NEURONS AND THEIR PHYLOGENY}

Dopamine is a catecholamine that is an amine derivative of catechol (2-hydroxyphenol). DA is certainly one of the oldest neurotransmitters, since it is being used as such in a very wide range of metazoans including diblastic species (Carlberg and Anctil, 1993). DA can also be a precursor of melanin pigments in many animals. For example, it plays a role in immunity and cuticle hardening in insects (Tang, 2009), and produces neuromelanin of the substantia nigra in humans (Fedorow et al., 2005).

Dopamine is derived from the aromatic amino acid tyrosine through two enzymatic stages. The first and limiting step is catalyzed by tyrosine hydroxylase [TH; an aromatic amino acid hydroxylase (AAAH)] and the second step is catalyzed by an aromatic amino acid decarboxylase (AADC; Figure 1A). Since the supply of tyrosine in food is short, most of the tyrosine used for dopamine synthesis is derived from another aromatic amino acid, phenylalanine, which is present ad libitum in food. Phenylalanine is transformed into tyrosine by the enzyme phenylalanine hydroxylase $(\mathrm{PAH})$, which is also a member of the AAAH family. 


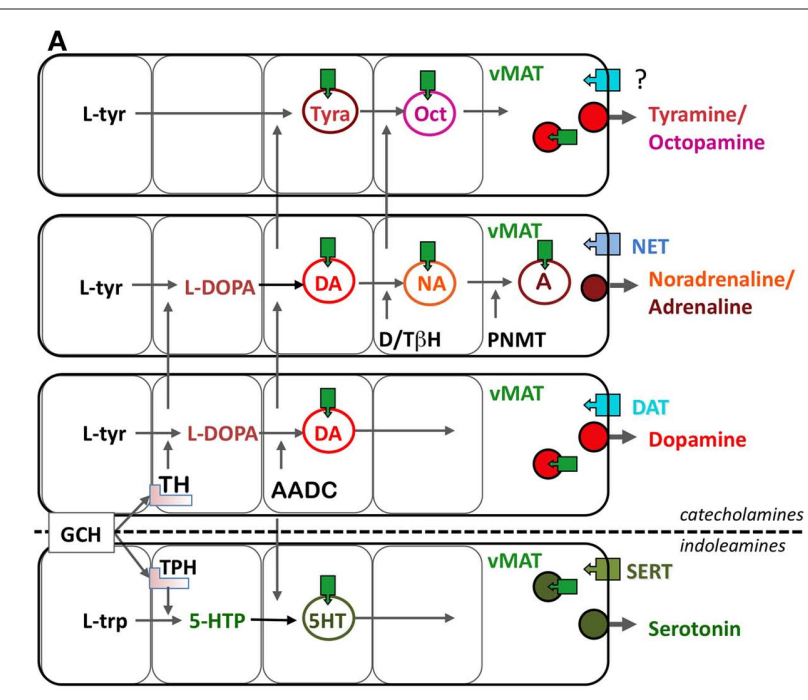

B

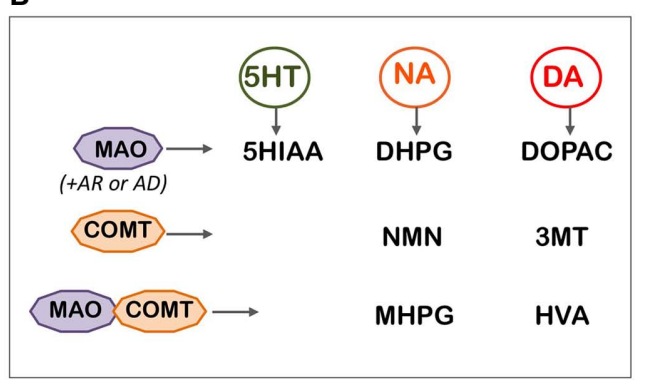

FIGURE 1 | Schematic representation of the metabolic (A) and catabolic (B) pathways of DA and other monoamines. (A) The biosynthesis of DA is highly modular and shares several molecular components with biosynthetic pathways of other monoamines. Catecholamines are synthesized from the aromatic amino acid l-tyrosine, and indoleamines synthesized from the aromatic amino acid l-tryptophan, but TH and TPH display many common characteristics, including the same co-factor (tetrahydrobiopterin, pinkish square under TH and TPH). Tyramine and octopamine come from the same pathways than the other catecholamines, without the primary action of $\mathrm{TH}$. Then, AADC and VMAT are components shared by all the pathways, including indoleamines. Finally, the membrane transporters, DAT, NET, and SERT, responsible for the re-uptake of the monoamines are more specific of the different monoamine pathways based on their cell-expression pattern, although their functional specificity is weak, especially for the DAT and NET (see text). (B) The catabolic enzymes are also essentially shared by all the monoamines. MAO is an intracellular enzyme, whose direct metabolites are rapidly transformed by aldehyde reductases $(A R)$ and aldehyde dehydrogenase (AD) in compounds (5HIAA for serotonin, DHPG for noradrenaline, and DOPAC for dopamine) easy to assay and which reflect the utilization of the transmitters. The effect of COMT, combined to that of MAO, provides metabolites assayable in body fluid such as CSF, blood, or urine, reflecting preferentially the utilization of monoamines at the periphery of the body. Abbreviations: 3MT, 3-methoxytyramine; 5HIAA, 5-hydroxy-acetic acid; 5-HTP, 5-hydroxytryptophan; AADC, aromatic amino acid decarboxylase; AD, aldehyde dehydrogenase; AR, aldehyde reductase; COMT, catechol-O-methyl transferase; DAT, dopamine transporter; DHPG, 3,4-dihydroxyphenyl-ethyleneglycol; DOPAC, 3,4-dihydroxyphenylacetate; D/T $\beta \mathrm{H}$, dopamine/tyramine $\beta$-hydroxylase; GCH, GTP cyclohydrolase; HVA, homovanillic acid; I-trp, I-tryptophan; I-tyr, I-tyrosine; MAO, monoamine oxidase; MHPG, 3-methoxy-4hydroxyphenyl-ethylene-glycol; NET, noradrenaline transporter; NMN, normetanephrine; Oct, octopamine; PNMT, phenylethanolamine- $N$-methyl transferase; SERT, serotonine transporter; TH, tyrosine hydroxylase; Tyra, tyramine; vMAT, vesicular monoamine transporter.
Dopamine is also a precursor of two other catecholamines, noradrenaline, and adrenaline. Noradrenaline is produced through the action of the enzyme dopamine/tyramine $\beta$-hydroxylase $(\mathrm{DBH})$. Adrenaline requires an additional step catalyzed by phenylethanolamine- $N$-methyl transferase (PNMT; Figure 1A). Catecholamines are included in a larger category of intercellular transmitters, the monoamines, which was initially defined by their property to be degraded by monoamine oxidases (MAO). Monoamines also comprise indolamines (e.g., serotonin, melatonin) and trace amines (tyramine, octopamine), the latter present in low amount in vertebrates. Histamine is also often included into the monoamines, although it is a diamine degraded by diamine oxidase.

The synthesized DA is then stored in synaptic vesicles by vesicular monoamine transporter 2 (vMAT2). DA is released at nerve terminal or dendrites upon neuronal depolarization. Neurotransmitter release is controlled by the synaptic machinery and triggered upon depolarization of the terminals and calcium entry (Pucak and Grace, 1994). The release of the different monoamines seems to depend on the differential contribution of synaptic molecules such as synapsins. This may be relevant to specific mode of release regulation depending on the monoamine neurotransmitters. Dendritic release also occurs by a vesicular mechanism controlled by local calcium concentration. Its role in regulating the presynaptic activity of dopamine neurons in areas such as the substantia nigra is critical to the overall regulation of mesostriatal, mesocortico-limbic systems, and related functions (Pucak and Grace, 1994). The released, extracellular DA is taken up by the dopamine transporter (DAT) located into the plasma membrane of nerve terminals, to terminate the neurotransmission. DA is then degraded inside the cells by monoamine oxidase (MAO) and catechol-O-methyl transferase (COMT).

Many of the molecular components used in dopamine neurotransmission are shared with the other monoamine neurons (Figure 1). This is the case for AADC, vMAT2, and MAO, for example. Other components of dopamine, noradrenaline, or serotonin neurons are members of the same gene/protein family. This is the case of dopamine, noradrenaline, and serotonin membrane transporters (DAT, NET, and SERT), or of the synthesizing enzymes TH, $\mathrm{TPH}$, and PAH. It is thus important to discuss the evolution of these molecules together. We here present the various molecular components such as synthesizing and catabolic enzymes, transporters, and receptors, which define the phenotype of the dopamine systems. We also present and discuss the phylogenies of the molecular components of monoamine systems.

\section{TYROSINE HYDROXYLASE (TH)}

The active form of $\mathrm{TH}$, as for the other AAAH, is a tetramer coordinated by one iron atom and binding a co-factor, tetrahydrobiopterin (BH4), synthesized by the enzyme GTP cyclohydrolase. TH sequence can be broadly divided into two domains, a catalytic C-terminal domain (two-third of the protein sequence), the structure of which has been resolved (Goodwill et al., 1997; Teigen et al., 2004) and which is highly conserved in all metazoans, and a $\mathrm{N}$-terminal regulatory domain which bears several phosphorylation sites, and which is much more variable, both in length and sequence (Kumer and Vrana, 1996). In vertebrates 
phosphorylation sites for the MAP kinase ERK, for the protein kinase $\mathrm{A}$, and protein kinase $\mathrm{C}$ are highly conserved, and in every species where it has been tested, $\mathrm{TH}$ phosphorylation is required for the enzyme to be active (Dunkley et al., 2004). In addition, in several vertebrate species - mostly mammals but also other amniotes - alternative splicing of the TH mRNA generates several isoforms of $\mathrm{TH}$, which allow a tissues-specific, differential regulation of TH activity by phosphorylation (Kumer and Vrana, 1996; Nakashima et al., 2009).

The structural requirements for enzyme activity impose heavy constraints on TH sequence, highlighted by its strong conservation in both protostomes and deuterostomes. Only one TH gene has been found in the protostomes. The protostome $\mathrm{TH}$ is clearly homologous to deuterostome $T H$ (including vertebrates), suggesting that the two animal groups share a common ancestral gene. In basal deuterostomes, only one TH gene has been found (in sea urchin, ascidia, and amphioxus for example), which is also a clear homolog of protostome and vertebrate $\mathrm{TH}$ genes. Inside vertebrates, the situation is more complex. Two $\mathrm{TH}$ genes ( $\mathrm{TH} 1$ and $T H 2$ ) have been recently shown to exist in most gnathostomes (jawed vertebrates) except in eutherian mammals (Candy and Collet, 2005; Yamamoto et al., 2010; Figure 2A). A TH2-related gene is indeed present in prototherians (platypus) and metatherians (opossum). Phylogenetic analyses and gene synteny strongly suggest that the two TH genes were duplicated before or close to the divergence of the jawed vertebrates, and secondarily lost in the eutherian lineage (Yamamoto et al., 2010). The exact timing of the duplication cannot be ascertained until completion of the genome sequence in agnathostomes (jawless vertebrate; e.g., lamprey). A recent study showed that the lamprey Petromyzon marinus possess at least one TH gene (Barreiro-Iglesias et al., 2010). The phylogenetic analysis shows that the lamprey $\mathrm{TH}$ gene belongs to the clade of $\mathrm{TH} 1$ of jawed vertebrates rather than being an outgroup of TH1 and TH2. This favors that the TH duplication occurred before the separation of the gnathostomes and agnathostomes. However, more genomic information is required to know if lamprey has second $\mathrm{TH}$ gene (Figure 2A).

Incidentally, the evolutionary history of $\mathrm{TH}$ genes is shared by the other members of AAAH family, PAH, and tryptophan hydroxylase (TPH), the key-enzyme of indoleamine biosynthesis. Only one copy of each AAAH gene $(T H, T P H, P A H)$ is found in the non-vertebrate bilaterians. In contrast, in most groups of jawed vertebrates, at least two $T H$ and $T P H$ genes are found, while PAH gene exhibits only one copy. Interestingly, the TPH1 gene is located on the same chromosome as TH1 (e.g., in human, chicken, and zebrafish), while TPH2 and PAH tend to be on the same chromosome as TH2. In case of non-mammals, $P A H$ and $\mathrm{TH} 2$ are next to each other on the same chromosome. It is thus likely that an ancestral chromosome was bearing the three genes ( $T H, T P H$, and $P A H$ ), and they have been duplicated early in the vertebrate evolution, probably corresponding to one of the whole genome duplications proposed to have occurred close to vertebrate emergence (Panopoulou and Poustka, 2005). Considering the presence of only one $P A H$ gene throughout the vertebrates, one copy of $P A H$ (close the TH1 locus) should have been lost early during vertebrate evolution, while the two TH and TPH genes were kept (TPH went through an additional duplication in the teleostean lineage). The evolution of the paralogous regions of the human chromosome 11 and 12 have been already described in relation to the evolution of AAAHs and insulin-related genes (Patton et al., 1998), and our observations are consistent with this hypothesis.

\section{AROMATIC AMINO ACID DECARBOXYLASE (AADC)}

The aromatic amino acid decarboxylase (AADC) catalyzes the transformation of L-DOPA into dopamine, and as such it is often called "DOPA decarboxylase" (encoded by the $d d c$ gene). However, it does not use only L-DOPA as a substrate, but also 5-HTP, the precursor of indoleamines such as serotonin (5HT). As for the catecholamines, AADC catalyzes the second step of 5HT synthesis, that is the transformation of 5-HTP into 5HT. It is a member of decarboxylase genes, which form a large protein family involved in the catabolism of amino acids, the products of which are also used as neurotransmitters (e.g., histidine decarboxylase for the synthesis of histamine, glutamate decarboxylase for GABA). The evolutionary history of orthologous and paralogous decarboxylase genes is rather complex (Saenz-de-Miera and Ayala, 2004). However, a bona fide AADC is present in both protostomes and deuterostomes, indicating that this enzyme was probably ancestral to all the bilaterians. It has been duplicated in insects (providing the paralogous amd gene) but not in deuterostomes including vertebrates. Although a single $d d c$ gene exists in all the vertebrates species analyzed so far, alternative transcription provides at least two forms of transcripts in mammals, one of them being specifically expressed in the nervous system.

\section{VESICULAR MONOAMINE TRANSPORTER}

Dopamine is actively transported into vesicles by exchange of protons across the vesicular membrane (two protons for one monoamine molecule) promoted by the vMAT2 (or slc18a2; reviewed in Parsons, 2000; Eiden et al., 2004). Two vMATgenes are present in jawed vertebrates, $v M A T 1$ ( $s l c 18 a 1)$ localized exclusively in peripheral neuroendocrine cells, and $v M A T 2$, present both in some neuroendocrine cells and in the neurons of the peripheral and CNS (Weihe and Eiden, 2000). vMAT2 is not specific to DA, but allows the accumulation of all sort of monoamines, with similar affinity and efficacy, leading to a 10,000 higher concentration of DA inside the vesicle than in the cytoplasm. In addition, the uptake of DA or other monoamines into vesicles protects the cells against the toxic effect of auto-oxidized monoamines, in particular quinones, which are important factors of oxidative stress and may predispose brain areas synthesizing high amounts of monoamines to neurodegenerative disorders, such as Parkinson's disease and supranuclear palsy for example (Vernier et al., 2004; Guillot and Miller, 2009). The existence of the two $v M A T$ genes ( $v M A T 1$ and $v M A T 2$ ) is certainly the result of a craniate/vertebrate duplication, as it was also the case for $\mathrm{TH}$ and other genes encoding monoaminergic markers (Figure 2A). But, again the duplication time cannot be inferred due to absence of data in jawless vertebrates. Orthologs of $v M A T$ are present in other chordates such as ascidians, and also in protostomes such as drosophila and Caenorhabditis elegans (Guillot and Miller, 2009) revealing that they are major components of the monoamine neurons throughout the evolution of bilaterian animals. 

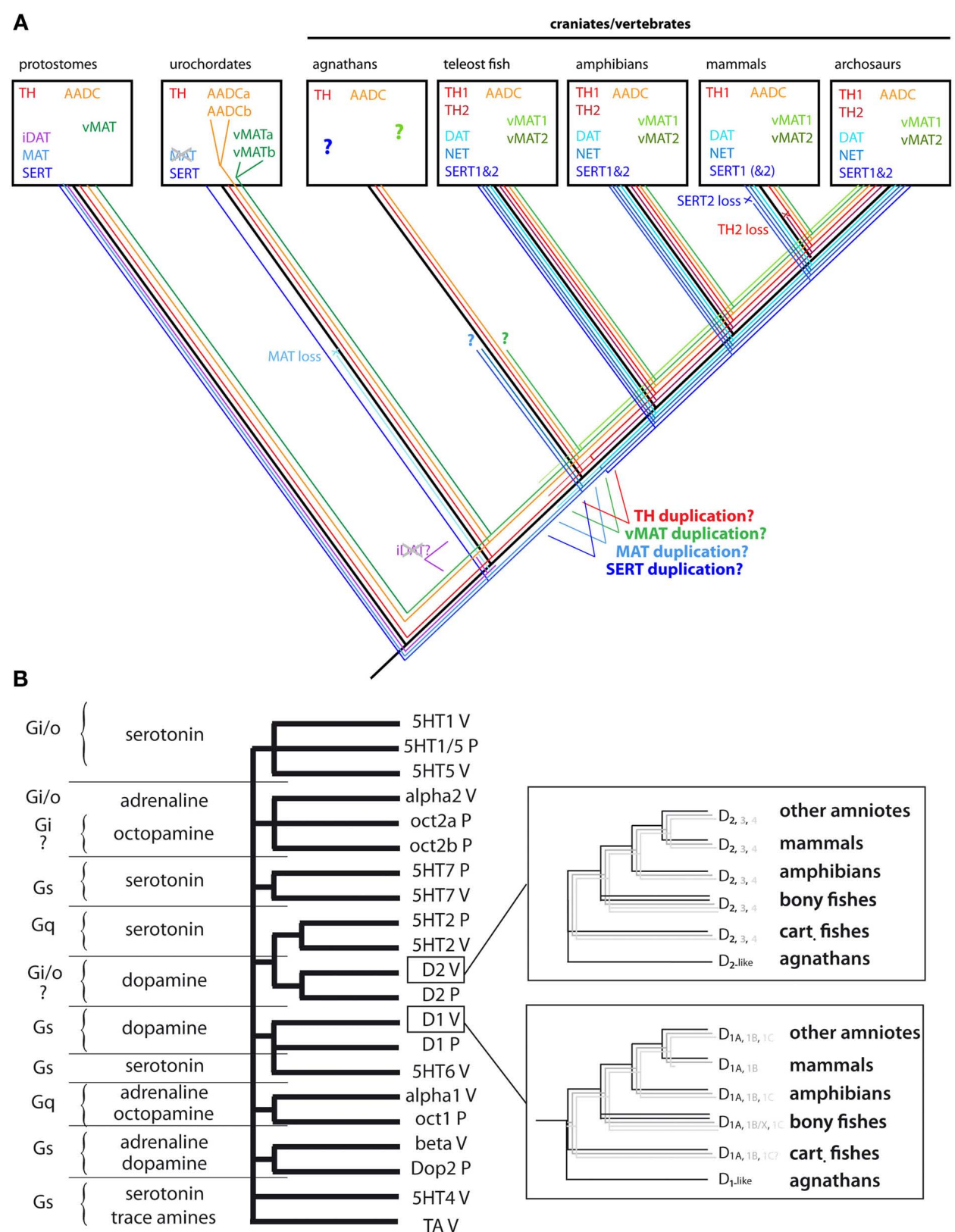

FIGURE 2 | Evolution of the molecular components of the monoaminergic systems in chordates. (A) Protochordates have all the basic molecular components of the monoamine pathways found in vertebrates. In urochordates, both MAT and iDAT do not exist but since MAT is present in amphioxus, it may have been lost specifically in urochordates. The loss of iDAT may have occurred earlier since it is not present in amphioxus. In vertebrates, MAT has been duplicated to provide DAT and NET, which are not thus orthologous to invertebrate iDAT but to invertebrate MAT. Similarly, SERT has been duplicated in jawed vertebrates. VMAT and AADC have been specifically duplicated in the urochordate lineage. Close to the emergence of vertebrates, TH, AADC, and VMAT have been duplicated. But since no genomic data are available yet in agnathans, it is currently impossible to known if this duplication took place before or after the emergence of jawed vertebrates. TH2 and SERT2 have been lost in placental mammals. Abbreviations and colors: AADC, aromatic amino acid decarboxylase (orange); iDAT and DAT, invertebrate form (i), and vertebrate form of dopamine transporter (light blue); MAT, monoamine transporter (blue); NET, noradrenaline transporter (blue); SERT, serotonine transporter (marine blue); $\mathrm{TH}$, tyrosine hydroxylase (red);
VMAT, vesicular monoamine transporter (green). (B) The molecular phylogeny of monoamine receptor in bilaterian animals reveals that most classes of monoamine receptors predated the origin of chordates and vertebrates. Classes of orthologous receptors in vertebrates and protostomes (most sequences come from ecdysozoan insects and nematodes) are transducing signals in cells via the same $\mathrm{G}$ protein (question marks correspond to the cases when the nature of $\mathrm{G}$ protein in not known), highlighting one of the major constraint on the conservation of the receptor sequences throughout bilaterian evolution. For example, $\alpha_{1}$ adrenergic receptors are orthologous to octopamine 1 receptors (Oct1) and $\alpha_{2}$ adrenergic receptors are orthologous to octopamine 2 receptors (Oct2), but both $\mathrm{D}_{1}$-like and $\mathrm{D}_{2}$-like receptors are also dopaminergic in protostomes. The topology of the tree also shows that receptor classes that bind the same natural ligand (e.g., DA) are not grouped together, suggesting that each class of receptor acquired independently and convergently the ability to bind a given neurotransmitter. Inside the rectangle, a simplified version of the phylogenetical relationships of the $D_{1}$ and $D_{2}$ receptor is presented. Three subtypes of receptor exist in each class, with the notable exception of mammals. 


\section{DOPAMINE TRANSPORTER}

After DA release into the extracellular space, the DAT (or slc6a3) located at the plasma membrane of nerve terminals is the main controller of the duration of the signal transmission, by taking up the extracellular neurotransmitter. In addition to DAT, two other monoamine transporters (MAT) exist in vertebrates, one for noradrenalin (NET or slca2) and one for serotonin (SERT or slc6a4), all belonging to the same protein family of solute carriers (slc6; Torres et al., 2003). The DAT has the capacity to transport both DA and noradrenaline, and the NET has an even better affinity for DA than noradrenaline (Apparsundaram et al., 1997; Roubert et al., 2001). However, both have several hundred orders of magnitude less affinity for serotonin.

In the mammalian prefrontal cortex (PFC), where DAT is found to be expressed at only a very low level, NET plays a major role for DA re-uptake (Moron et al., 2002; Carboni and Silvagni, 2004; Valentini et al., 2004). Also, when a given membrane MAT has been blocked or inactivated, the other remaining transporters are able to compensate, at least partially for the transporter loss-offunction (Sulzer and Edwards, 2005). Re-uptake of DA and NA by SERT (Vizi et al., 2004; Kannari et al., 2006), and re-uptake of 5HT by DAT and NET (Daws et al., 1998; Zhou et al., 2005; Mossner et al., 2006) have been described. Also, in the protochordate ascidia, SERT is expressed in DA-synthesizing cells of the sensory vesicle (Razy-Krajka et al., unpublished). When the evolution of these gene families is taken into account, these heterologous interactions may not be so surprising, given the close relationships between many of these monoaminergic markers, several of which are used simultaneously by several biosynthetic pathways.

The evolution of membrane MAT has been well documented (Caveney et al., 2006), although some refinements can be made owing to recent genome data. Molecular phylogenies of MAT-related sequences show the existence of three classes of molecules inside the slc6 clade; a DAT restricted to invertebrates (iDAT), and two other groups of transporters, a catecholamine/phenolamine MAT, and an SERT. Vertebrate DAT and NET belong to the MAT branch, and there is no ortholog of the iDAT branch in vertebrates. Thus gene encoding DAT in vertebrates and in protostomes (iDAT) are not orthologous, but paralogous. It is suggested that the three genes iDAT, MAT, and SERT were present in basal bilaterians. In the chordate lineage, iDAT was lost while MAT was kept. MAT was then duplicated early in vertebrate evolution to give rise to DAT and NET found in contemporary vertebrates. The duplication occurred probably after separation of the cephalochordate lineage, because only one MAT gene is present in the amphioxus genome. In urochordates (e.g., ascidians), only SERT has been found but no other MAT-related sequences, and these species thus seem to have secondarily lost MAT at their ancestral stage. Finally SERT is likely to be duplicated in the stem vertebrate since two copies of SERT (SERT1 and SERT2) are found in each taxon except eutherian mammals (Caveney et al., 2006; our unpublished data). Gene synteny supports the lost of SERT2 in eutherian mammals, in a way reminiscent of the evolutionary history of TH in mammals (see above; Caveney et al., 2006).

\section{DEGRADATION ENZYMES: MONOAMINE OXIDASE (MAO)}

Dopamine, when freed into the cytoplasm, can be degraded into 3,4-dihydroxyphenylacetaldehyde (DOPAL), by monoamine oxidase (MAO), an homodimeric enzyme using FAD as co-factor and located on the external membrane of mitochondria. DOPAL is further oxidized by aldehyde dehydrogenase to 3,4-dihydroxyphenylacetate (DOPAC), often used as an index of DA catabolism and turn-over (reviewed in Nagatsu, 2004). Two MAO exist in most vertebrate species, MAO-A and MAO-B, with different relative affinities for catecholamines and indoleamines. MAO-A preferentially oxidizes phenylethylamine and DA, and it is located mostly in catecholamine-containing cell groups, such as the substantia nigra, the locus coeruleus, or the periventricular region of the hypothalamus. MAO-B uses 5HT as a degradation substrate and is localized mostly in serotoninergic neurons of the raphe nuclei, for example (Westlund et al., 1985; Willoughby et al., 1988; Anichtchik et al., 2006). The gene duplication that gave rise to the two MAOparalogs is a tandem duplication, as evidenced in the sequenced genomes of amniotes and amphibians (on the X chromosome in human). Interestingly, only one MAO exists in several teleost fish, with functional characteristics clearly closer to those of MAO-A than to those of MAO-B (Anichtchik et al., 2006; Sallinen et al., 2009). Whether the duplication of the MAO gene in vertebrates occurred before of after the emergence of teleosts cannot be established presently. However, it has to be stressed that MAO present in teleosts is mostly used in the 5HT system to regulate its metabolism, and its precise role in the regulation of the metabolism of other monoamines, including DA, needs to be investigated further.

The presence of MAO-A and -B is of importance for human pathophysiology since the neurotoxic MPTP is metabolized by $\mathrm{MAO}-\mathrm{A}$ into $\mathrm{MMP}^{+}$in non-dopaminergic neurons, but it becomes toxic when taken up by DAT (and not NET or SERT) into DA neurons, where it promotes mitochondria-dependent apoptosis and a syndrome close to idiopathic Parkinson's disease. Accordingly, different species have differential susceptibility to MPTP, zebrafish, mouse, and primates being rather sensitive to the toxic, but rats are much more resistant, for example.

Since MAO sequence has not been described yet in cartilaginous fish or in jawless vertebrates, it is not clear when the duplication of two MAO genes occurred. Since there is only one MAO gene in teleosts, it is possible that the duplication happened in the tetrapod lineage. In addition, the evolutionary origin of the vertebrate MAO is unclear since no ortholog of vertebrate MAO exists in protostomes (MacHeroux et al., 2001). However, a vertebrate-like MAO exists in protochordate genomes (amphioxus and ascidian, unpublished). Thus, it may be possible that an ancestral L-amino acid oxidase (another member of flavin-containing amine oxidoreductases) has been co-opted in the deuterostome lineage leading to protochordates and vertebrates. Then this MAO has been conserved in chordates, with the occurrence of MAO duplication in jawed vertebrates.

DEGRADATION ENZYMES: CATECHOL-O-METHYL TRANSFERASE (COMT)

Dopamine can also be degraded into 3-methoxytyramine (3-MT) by catechol-O-methyl transferase (COMT) located essentially at extraneuronal sites. COMT is an intracellular enzyme that catalyzes the transfer of a methyl group from $S$-adenosylmethionine to catecholamines, either the neurotransmitters or xenobiotic catechols. COMT has a very widespread distribution in the vertebrate body, and its distribution, even in the CNS is mostly non-neuronal. The combined action of MAO and COMT on dopamine yield one of 
its most commonly measured extracellular metabolites, homovanillic acid (HVA). The balance of neurotransmitter production, recycling, and degradation is reflected in the ratio of the DOPAC or HVA metabolites to neurotransmitter, and these metabolites can be assayed in the cerebrospinal fluid (CSF) or the blood as a reflection of DA metabolism and dysfunction (Eisenhofer et al., 1985).

In mammals, COMT is found in two forms in cells, a soluble form and a membrane-bound form, generated by different gene promoters and alternative translation initiation sites. As far as we know, there is only one gene in the available genome sequences of jawed vertebrates. Orthologous COMT sequences are present in protochordates, but they are not found in sea urchin genome sequences or in the protostome genomes sequenced so far. Thus, as for MAO, it is possible that a COMT was acquired only in the chordate lineage, transformed from one of the numerous methyl transferase genes found in most living species.

To summarize our view of the evolution of the molecular components of the DA metabolic pathways, it could be stressed that several of the corresponding genes have been duplicated in jawed vertebrates (TH, TPH, vMAT, membrane transporters, MAO, but not AADC and COMT). These duplicated genes exhibit a clear differential expression in the vertebrate brain, reflecting both subfunctionalization and neofunctionalization. These derived characters drove the conservation of the duplicated genes, and were probably used for adaptation of the DA systems to the large anatomical and functional changes that can be evidenced in the different groups of vertebrates. In this respect, it is quite remarkable that placental mammals have lost most of these duplicated genes. It is very likely that placental mammals have found different ways of using highly adaptive DA systems than the other jawed vertebrates do.

\section{DOPAMINE RECEPTORS}

Most of the cellular receptors for monoamines are membrane proteins with seven transmembrane segments coupled to heterotrimeric $\mathrm{G}$ protein ( $\mathrm{G}$ protein coupled receptors or GPCR). GPCRs act as exchange factors for $G$ proteins that regulate many different cellular processes or signaling pathways (Neves et al., 2002). The dopamine receptors are divided into two classes of GPCR, $\mathrm{D}_{1}$ - and $\mathrm{D}_{2}$-class receptors (reviewed in Missale et al., 1998; Callier et al., 2003). Members of the $D_{1}$ receptor class are structurally characterized by a short third cytoplasmic loop and a very long C-terminal tail. They are coupled to the $\mathrm{G}_{\mathrm{s}} / \mathrm{G}_{\text {olf }}$ class of $\mathrm{G}$ proteins and accordingly they activate adenylyl cyclase. In contrast, receptors of the $\mathrm{D}_{2}$ class are coupled to $G_{i} / G_{o}$ proteins and they display a long third cytoplasmic loop and a short cytoplasmic C-terminal end. $\mathrm{D}_{2}$ receptors have been initially described as mediating adenylyl cyclase inhibition, but their major cellular effects in adult vertebrates are the modulation of neuronal excitability through inhibition of voltagesensitive $\mathrm{Ca}^{++}$and activation of $\mathrm{K}^{+}$channels. $\mathrm{D}_{2}$-like receptors are able to regulate other signaling pathways related to changes of cell shape or mitosis (Missale et al., 1998; O’Keeffe et al., 2009).

The nomenclature of DA receptors is quite confusing. Originally one excitatory and one inhibitory DA subtype were found, and they are named to be $\mathrm{D}_{1}$ and $\mathrm{D}_{2}$. Molecular cloning techniques led finding of additional subtypes, and they were named $\mathrm{D}_{3}, \mathrm{D}_{4}$, and $\mathrm{D}_{5}$, however, later characterization of the subtypes defined that $D_{5}$ is rather close to $D_{1}\left(D_{1}\right.$-class $)$ and $D_{3}$ and $D_{4}$ are close to $D_{2}$
( $\mathrm{D}_{2}$-class). $\mathrm{D}_{1}$ and $\mathrm{D}_{5}$ are often called $\mathrm{D}_{1 \mathrm{~A}}$ and $\mathrm{D}_{1 \mathrm{~B}}$ respectively in non-human, and especially in non-mammalian vertebrate species, according findings of additional $\mathrm{D}_{1}$-class receptors; $\mathrm{D}_{1 \mathrm{C}}$ (Xenopus; Sugamori et al., 1994), D (chicken; Demchyshyn et al., 1995), and $\mathrm{D}_{1 \mathrm{X}}$ (carp; Hirano et al., 1998).

Molecular phylogenies are the best way to classify the DA receptors, especially when analyzed together with other classes of monoamine receptors; the adrenergic $\left(\alpha_{1}, \alpha_{2}, \beta\right)$, serotoninergic $\left(5 \mathrm{HT}_{1}, 5 \mathrm{HT}_{2}, 5 \mathrm{HT}_{4}, 5 \mathrm{HT}_{5}, 5 \mathrm{HT}_{6}\right.$, and $\left.5 \mathrm{HT}_{7}\right)$, or trace amine receptors. A first important observation made by such a molecular analysis is that the different receptor classes binding the same neurotransmitter $\left(D_{1}\right.$ and $D_{2}$ receptors for example) are not more related to each other than to other classes of monoamine receptors (Figure 2B). This observation implicates that DA receptors have acquired independently (by convergence) the ability to bind DA, as it was also the case for the other classes of monoamine GPCR.

Inside each class of monoamine receptors, several subtypes exist in jawed vertebrates $\left(D_{1 A}, D_{1 B}, D_{1 C}, D_{1 D}\right.$, and $D_{1 X}$ in the $D_{1}$ receptor class for example), which resulted from gene duplications that had occurred rather early in the vertebrate lineage. Amphioxus possesses only one $\mathrm{D}_{1}$-like gene (AmphiAmR1; Burman et al., 2009) which is an outgroup of all the $\mathrm{D}_{1}$ receptor subtypes of vertebrates. Since the genome sequence data currently available for jawless vertebrates such as lamprey or hagfish are too scarce, it is impossible to draw a reliable assumption about the timing of the duplication of the ancestral receptor genes. Several molecular phylogenies and hypotheses on their evolution have been published (Callier et al., 2003; Le Crom et al., 2003). However, recent findings changed our view of the $\mathrm{D}_{1}$ receptor relationships.

It was previously thought that $\mathrm{D}_{1 \mathrm{C}}$ and $\mathrm{D}_{1 \mathrm{D}}$ were different subtypes, based on their distinct pharmacological and cellular functional characteristics as well as on molecular phylogenies using a limited number of species. However, recent phylogenic analyses including more sequences from a larger range of species, as well better knowledge of gene synteny, strongly suggest that $\mathrm{D}_{1 \mathrm{C}}$ (mostly found in anamniotes) and $\mathrm{D}_{1 \mathrm{D}}$ receptor subtypes (described in sauropsids) are in fact encoded by orthologous genes (Yamamoto et al., unpublished). The $\mathrm{D}_{1 \mathrm{C} / \mathrm{D}}$ receptor subtype is found in all the jawed vertebrate groups except mammals, and thus likely to have been secondarily lost in the mammalian lineage. Teleost fishes possess additional copies of $\mathrm{D}_{1}$ receptor genes. This fact is most likely to be a consequence of the teleost-specific genome duplication (Postlethwait et al., 2000; Vandepoele et al., 2004; Volff, 2005). In addition, a phylogenic analysis suggests that the $D_{1 X}$ receptor gene, which is found only in teleost genomes, may be a paralog of the vertebrate $D_{1 B}$ receptor gene (Yamamoto et al., in preparation). Thus, the molecular phylogeny of the $\mathrm{D}_{1}$ receptors class may now be simplified to three subtypes; the $\mathrm{D}_{1 \mathrm{~A}}, \mathrm{D} 1_{\mathrm{B} / \mathrm{X}}$, and $\mathrm{D}_{1 \mathrm{C} / \mathrm{D}}$ receptor subtypes. As for the molecular components of the DA metabolism, it should be mentioned that mammals have reduced the genetic diversity of the dopamine receptors as compared to the other groups of jawed vertebrates, at odd with the common view that mammals, especially human, could be more "complex" than the other vertebrates groups.

Similar overall statements could be made for the $\mathrm{D}_{2}$-class receptors. The $\mathrm{D}_{2}$-class receptors comprise three subtypes in jawed vertebrates, the $\mathrm{D}_{2}, \mathrm{D}_{3}$, and $\mathrm{D}_{4}$ receptor subtypes (more 
logically to be named $\mathrm{D}_{2 \mathrm{~A}}, \mathrm{D}_{2 \mathrm{~B}}, \mathrm{D}_{2 \mathrm{C}}$, which were envisaged at one time, but not retained by usage). These $\mathrm{D}_{2}$ receptor subtypes are found in most of the sequenced vertebrate species, thus it is likely that the ancestral jawed vertebrates already possessed all of them. Additional duplication within the subtypes occurred specifically in the teleost lineage, with many species-specific differences. While many fishes possess two to three paralogs of $D_{2}$ and $\mathrm{D}_{4}$ receptor genes, there is only one $\mathrm{D}_{3}$ receptor gene in all teleosts analyzed so far. The timing of the duplication giving rise to the three $\mathrm{D}_{2}$-like receptor subtypes is unclear, as only one $\mathrm{D}_{2}$-like receptor has been found in lamprey. In addition, there is no $\mathrm{D}_{2}$-like receptor gene found in protochordates so far (in ascidians and amphioxus published genomes). It is, however, very likely to be a secondary loss in the protochordate lineage, since protostomes have $\mathrm{D}_{2}$ receptor orthologs.

Finally, as described above for the transporters, some heterologous interactions with other monoamine systems also exist for the receptors. In several vertebrates, it has been shown that DA can interact with adrenergic receptors, either $\alpha_{1}$ (Ruffolo and Morgan, 1984; Aguayo and Grossie, 1994; Rey et al., 2001), $\alpha_{2}$ (Ruffolo and Morgan, 1984; Aguayo and Grossie, 1994; Zhang et al., 1999; Rey et al., 2001; Cornil et al., 2005; Cornil and Ball, 2008), or $\beta$ (Ruffolo and Morgan, 1984; Lee et al., 1998) adrenergic receptors. Conversely, noradrenaline and adrenaline can interact with $\mathrm{D}_{1}$ or $\mathrm{D}_{2}$ receptors (Lanau et al., 1997; Newman-Tancredi et al., 1997). Indeed the chemical differences between the natural catecholaminergic ligands are not huge, and the binding site of one class of receptors has some degree of flexibility and adaptability to accommodate related ligands (Xhaard et al., 2006). The heterologous ligand-receptor interactions are probably less efficient compared to the homologous interaction (for example, affinity of dopamine to adrenergic $\alpha_{2}$ receptor is 3-30 times less than that of noradrenaline), nonetheless, they can play a physiologically significant role in the brain. It has been demonstrated that DA modulates quail male sexual behaviors via $\alpha_{2}$ adrenergic receptors in the preoptic area (Cornil et al., 2005).

\section{COMPARATIVE ANATOMY OF DOPAMINE SYSTEMS IN VERTEBRATES}

The localization of monoamine neurotransmitters including DA was first demonstrated by histochemical detection of MAO. According to the improved formaldehyde-induced fluorescence (FIF) method, catecholaminergic cell populations were described in the rat brain and designated as A1-A12 from the medulla oblongata to the hypothalamus (Dahlstrom and Fuxe, 1964). Later development of specific antibodies recognizing individual catecholamine enzymes revealed additional A13-A17 cell groups (Björklund and Lindvall, 1984; Hökfelt et al., 1984). This nomenclature is still often used, because DAergic cells are not always located in a single distinct nucleus, and also because the distribution of the cell groups remarkably varies even among mammalian species. Indeed a one to one homology is difficult to determine among distant vertebrate groups, and some caution should be kept, since similar hodologi$\mathrm{cal} /$ functional aspects of DA systems in different vertebrate groups may be the result of conservation, but alternatively of convergence (see Figure 3).
Extensive reviews have been given of the distribution and organization of DA cell groups in the vertebrate brain (Smeets and Reiner, 1994; Smeets and González, 2000). In this paper, we are restricting our overview to the DAergic neurons of the forebrain and midbrain. As mentioned above, all the TH immunopositive cells in the forebrain and midbrain have been considered to be DAergic, because there is no DBH or PNMT immunoreactivity anterior to the midbrain-hindbrain boundary (MHB). DA cells are generally categorized into the diencephalo-midbrain (A8-A10), diencephalic (A11-A15), olfactory bulb (A16), and retinal (A17) cell groups (Smeets and González, 2000).

Note that the "diencephalon" is defined here in a classical manner (dividing the forebrain into diencephalon and telencephalon) to be consistent with previous works. In this view, the diencephalon includes the pretectal area, thalamus, hypothalamus, and preoptic areas. Then retinal DA cells (A17) can be included in one of the diencephalic DA cell groups, because retina is ontogenetically derived from a territory shared with the hypothalamic anlage. In contrast, the formation of neuromeres during the development of the neural tube allows to describe the forebrain regions as segmented from posterior to anterior into three prosomeres ( $\mathrm{p} 1, \mathrm{p} 2$, and $\mathrm{p} 3$ ), and the secondary prosencephalon. Within this frame, the pretectum, thalamus (dorsal thalamus), and prethalamus (ventral thalamus) are the alar part of the $\mathrm{p} 1, \mathrm{p} 2$, and $\mathrm{p} 3$ prosomeres respectively, while the hypothalamic and preoptic areas are part of the secondary prosencephalon together with the telencephalon (Puelles and Rubenstein, 2003; Medina, 2008).

\section{DIFFERENTIAL EXPRESSION OF TH1 AND TH2 IN THE BRAIN OF VERTEBRATES}

It is worth noticing that the DA-synthesizing cell groups described in most publications were expressing the $\mathrm{TH} 1 \mathrm{form}$ of $\mathrm{TH}$, and that TH2-expressing cell populations should be now added to be DA cell groups. Recent accounts demonstrated that the cell populations containing the $\mathrm{TH} 2$ transcripts are not (or very poorly) labeled by commercially available $\mathrm{TH}$ antibodies due to their low affinity for the TH2 protein (Yamamoto et al., 2010). Nevertheless, labeling of $\mathrm{TH} 2$ transcripts are co-localized with DA immunoreactivity in the zebrafish brain (Yamamoto et al., 2010, 2011). TH2 expression is found exclusively in the periventricular zone of diencephalic areas, and its distribution pattern is extremely similar to what has been described as "DA accumulating" CSF-contacting cells found in various non-vertebrate species (Meek, 1994; Smeets and Reiner, 1994; Smeets and González, 2000). Indeed, due to the lack of TH immunolabeling, these DA-immunopositive cells have been considered to accumulate extracellular DA, instead of synthesizing it. Our current knowledge about TH2 expression strongly suggests that they are in fact DA-synthesizing cells (Yamamoto et al., 2011). Although such data have been obtained in zebrafish only and need to be replicated in other species, the presence of the $\mathrm{TH} 2$ gene in all the non-eutherian classes of jawed vertebrates suggests that the CSF-contacting DA cell populations are common and ancestral to jawed vertebrates. The TH2 gene has been lost in eutherian mammals (Yamamoto et al., 2010) and one could speculate that adaptation in eutherian mammals, by weakening the physiological role of the TH2-expressing cell populations, was a key-factor of the corresponding gene loss. However, the function of the TH2 cells in 


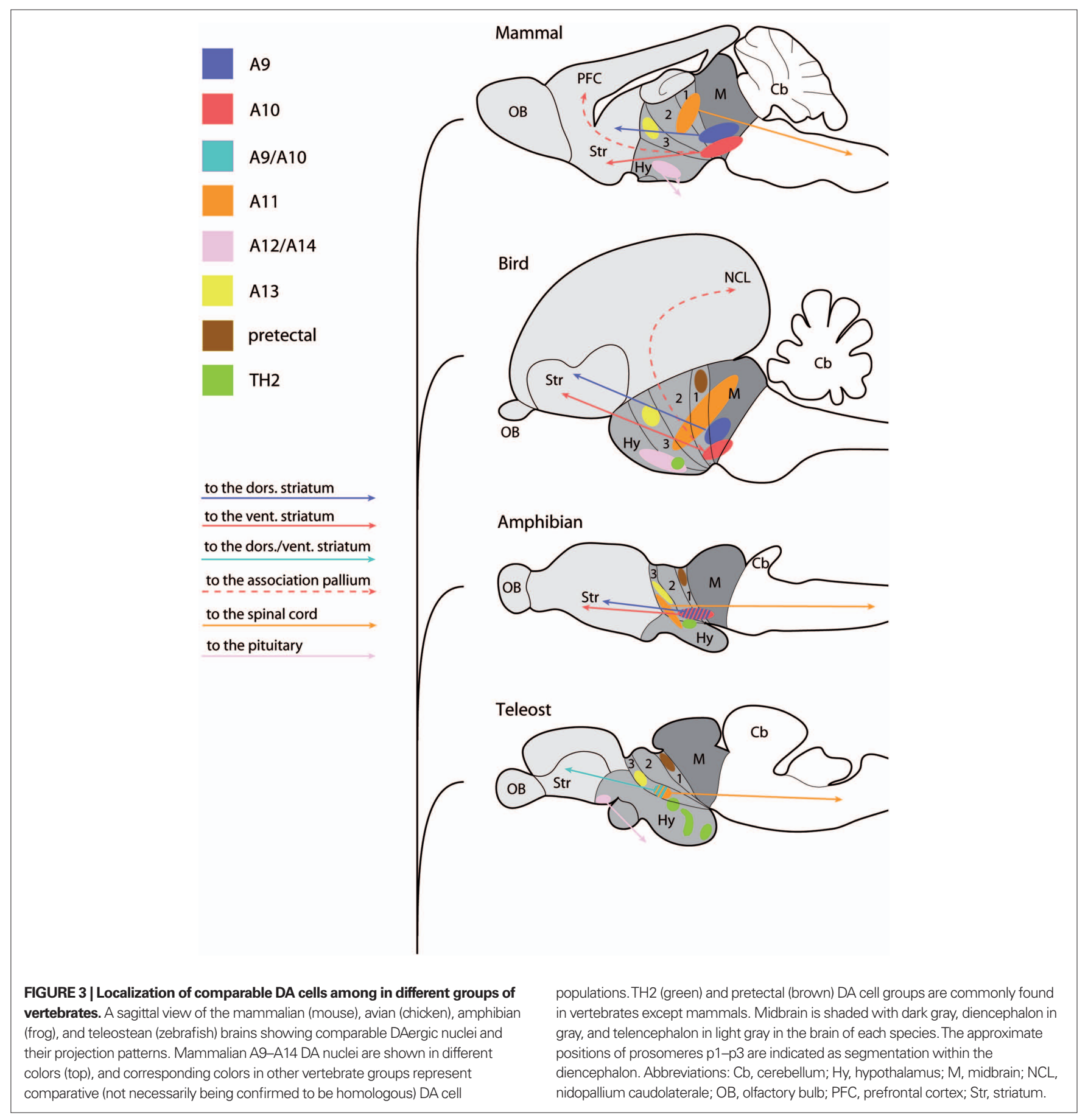

non-eutherian species is unknown, although they may play a role in hypothalamo-hypophyseal regulation as some other hypothalamic CSF-contacting cells do (Vigh-Teichmann and Vigh, 1983).

Except for these restricted TH2 cell populations in the hypothalamic and preoptic areas, the distribution of TH- or DA-immunolabeled cells overlaps with that of $\mathrm{TH} 1$ expression, at least at a regional level. All vertebrate species examined so far possess DA cells in the classical diencephalic areas including the retina, and the olfactory bulb, while teleosts and lampreys are lacking DA cells in the midbrain. Often, DAergic cell populations in the telencephalon (other than the olfactory bulb) are not cited, because there is no detectable $\mathrm{TH}$ cell in the adult rat or mouse brains. However, pallial and subpallial DA cells have been found in the lampreys, cartilaginous fishes, and teleosts, and also in primates including humans (Gaspar et al., 1987; Dubach, 1994), although their functions are unknown.

\section{DA CELLS OF THE RETINA}

The DA-synthesizing cells in the retina have been found in all the vertebrate species studied so far, including lamprey, with the notable exception of hagfish (Holmberg, 1970; Smeets and González, 
2000). Since hagfish are living mostly in the dark and exhibit a highly simplified retina, the absence of DA cells could be a loss in this specific group. Two categories of DA cells have been described in the vertebrate retina, the amacrine cells generally located in the inner nuclear layer or somewhat displaced in the inner plexiform layer, and the interplexiform cells (Masland, 2001). Teleost fish and lampreys have only this latter type of retinal DA cells, whereas typical amacrine cells are found in cartilaginous fishes, amphibians, and amniotes. It now appears that these anatomically distinct cell types have the same ontogenetic origin, and they are all considered as amacrine DA cells (Agathocleous and Harris, 2009). They generally express the whole range of DA markers, although they very often co-express GABA and some of them are able to accumulate 5HT in addition to DA (Huang and Moody, 1998). The amacrine DA cells play a major and conserved role in retinal adaption to light by affecting mechanisms such as retinomotor movements or changes of the size of the receptive fields (Masland, 2001).

\section{DA CELLS OF THE OLFACTORY BULB}

Dopamine cells have been found in the olfactory bulb of representatives of all the craniates/vertebrates groups. The DA cells are generally located in a juxtaglomerular position, but they are also found more in the external plexiform layer and in the internal granular layers. There is a considerable diversity in the general location of these DA neurons across species, and very often these cells do not display all DA markers together. In some species, TH immunoreactive cells largely exceed in number the DA positive cells, and in many species, AADC and vMAT2 are poorly expressed (Smeets and González, 2000; Yamamoto et al., 2011). For these reasons, it has been proposed that some TH-expressing neurons of the olfactory bulb could synthesize L-DOPA but not DA (Smeets and Reiner, 1994). In addition, the phenotype of olfactory bulb DA cells is very plastic and changes fast with cellular activities (Cave and Baker, 2009). Neural precursors of the DA cells of the olfactory bulb arise from the subventricular zone of the telencephalon and migrate to the olfactory bulb by the rostral migratory stream. This neurogenesis persists all life long in all vertebrates studied so far, and it is strongly affected by activity (Lazarini and Lledo, 2011). It is thus also possible that some of the discrepancy found for the phenotypes of the DA in the olfactory bulb reflects activity-related changes.

\section{DIENCEPHALIC CELL GROUPS (A11-A15)}

Diencephalic DA cell groups consist of five groups in mammals; A11 (caudal diencephalic cell group, giving rise to diencephalospinal projections), A12 (tuberal cell group, tubero-infundibular projection), A13 (prethalamic/ventral thalamic cell group; incertohypothalamic projection), A14 (rostral periventricular cell group, tubero-hypophysial projection), and A15 (lateral and ventral hypothalamus, local projection in the diencephalon; Björklund and Lindvall, 1984). However, the boundaries of the cell groups are not always clear and, for example, there is no obvious separation between A11 and A13 in some species (Tillet, 1994).

Most of the proposed homologs of A11-A15 in amniotes are based on the topology of TH (TH1) immunoreactive cells (Kiss and Peczely, 1987; Medina et al., 1994; Reiner et al., 1994), although the projections and functional aspects remain to be investigated. One to one comparison with anamniotes is more difficult due to the variation of the brain morphologies. Increasing knowledge of the neuropeptide content, projection patterns, and gene expression profiles allow us, to some extent, to compare the DA nuclei of amniotes and anamniotes.

Dopamine neurons are commonly found in the ventral thalamic area in all the vertebrate groups, which are likely to be homologous to the A13 group (shown in yellow in Figure 3). Both mammalian A13 and amphibian ventromedial nucleus (in the alar domain of p3) co-express TH and somatostatin (Inagaki et al., 1981; Meister et al., 1987; Petko and Orosz, 1996). In addition, DA cells of ventral thalamus in zebrafish are located close to Pax6 immunoreactive cells (Wullimann and Rink, 2001), as is the case in the A13 cells in mammals (although half of them co-localize with Pax6 unlike in the zebrafish ventral thalamus; Vitalis et al., 2000).

Similarly, DA cells located in the periventricular gray matter extending from the mesencephalon to $\mathrm{p} 3$ are found in many vertebrates, and they may correspond to the A11 group (reviewed in Smeets and González, 2000). In zebrafish, several diencephalic DA cell groups (located in $\mathrm{p} 3$ and hypothalamus), have been proposed to be similar to the mammalian A11 cells (DA groups 2, 4, 5, 6; Ryu et al., 2007; reviewed in Schweitzer and Driever, 2009). These posterior tubercular/hypothalamic DA cells in zebrafish require the transcription factor Orthopedia (Otp) as well as Nkx2.1 for their specification, as it is the case for the mouse A11 (Ryu et al., 2007; Löhr et al., 2009). Furthermore, mammalian A11 is characterized by distal projections to the spinal cord, and cells in the periventricular nucleus of posterior tuberculum (TPp) project to the spinal cord in zebrafish (Becker et al., 1997; Tay et al., 2011). These data indicate that these DA cells of zebrafish posterior tuberculum may be equivalent to the A11 of mammals. A11-like catecholaminergic projections to the spinal cord are found in amphibians as well, and the cell bodies are located in $\mathrm{p} 3$ and hypothalamic areas (Sanchez-Camacho et al., 2001), similar to the case in zebrafish. The diencephalo-spinal DA projections are also found in lampreys, but these cells are CSFcontacting neurons, unlike in jawed vertebrates. Thus, although diencephalo-spinal DA systems are commonly found throughout the vertebrates, the homology is currently unclear.

The A12 and A14 DA cells (which are respectively located in the arcuate nucleus and periventricular hypothalamic nucleus in rodents) are well studied and known to regulate prolactin, growth hormone $(\mathrm{GH})$ or gonadotrophins, luteinizing hormone (LH), and follicle stimulating hormone ( $\mathrm{FSH}$ ) in the pituitary (Ben-Jonathan and Hnasko, 2001; Thiery et al., 2002; Dufour et al., 2005; GarciaTornadu et al., 2010; Zohar et al., 2010). In amniotes, the A12 cells project to the median eminence where they release DA in the portal blood vessels and regulate some of the anterior pituitary cell populations, whereas A14 send direct projections to the posterior pituitary (intermediate and neural lobes; Zohar et al., 2010). In teleosts, a DAergic regulation similar to that exerted by the A12 cells pituitary is found, with some differences in the projection pattern of the neuronal fibers (review in Busby et al., 2010). In teleosts, the DA cells of the anteroventral part of the preoptic area (PPa) negatively regulate $\mathrm{LH}$ release in the anterior pituitary as A12 DA cells, however, unlike mammalian A12, the teleost PPa cells send direct projections to the anterior pituitary (Kah et al., 1984). Many of the DA effects on the pituitary are exerted through the $\mathrm{D}_{2}$ receptors, and they inhibit the secretion of various pituitary hormones, although 
there are variations (Busby et al., 2010; Dufour et al., 2010; Zohar et al., 2010). The significance of the DA control on the hypophysis varies depending on the life style of the animals. For example, the DA effects on prolactin is important for regulating lactation in mammals, which is obviously not the case for fish. Instead, DA regulation on prolactin plays an important role for osmoregulation in fish (Liu et al., 2006), and it is probably an ancestral function of hypothalamic DA neurons in vertebrates.

Not much is known about the function A15 cell populations. Their projections are mainly to other diencephalic areas. A15 is the most rostral part of the diencephalic DA cells, and they are located around the optic chiasm including the supraoptic nucleus in mammals. DA cells are consistently found around the supraoptic/ suprachiasmatic regions in various vertebrates, and it is possible that they correspond to A15.

In addition to the A11-A15 nuclei, a pretectal DA cell group (alar plate of p1) is consistently found in bony fishes, amphibians, and most amniotes except mammals (reviewed in Smeets and González, 2000). These pretectal neurons are projecting mostly on the optic tectum, in a layer-specific fashion, and they may play a role in the modulation of the retino-tectal visual input (Smeets and Reiner, 1994). In the group of species where no pretectal DA neurons are found (cartilaginous fish and mammals), DA neurons are found in the habenular area, although no role are known for those neurons (Stuesse et al., 1994). However, it is likely that the pretectal DA neuronal population is an ancestral trait of jawed vertebrates (Smeets and Reiner, 1994).

\section{MESENCEPHALO-DIENCEPHALIC CELL GROUPS (A8-A10)}

The midbrain populations of DA neurons are the most intensively studied, due to their major contribution to the pathophysiology of Parkinson's disease (Obeso et al., 2010), and also to the mechanisms of drug addition and other psychiatric disorders (schizophrenia, attention deficit with hyperactivity; Wise, 2009). It must be recalled that A8-A10 cells are often called "midbrain" DA cell groups although they are not restricted to the midbrain. Instead, they extend to the ventral diencephalic territories (Medina et al., 1994; Puelles and Medina, 1994; Verney et al., 2001; Vernier and Wullimann, 2009). The DA cell groups of the midbrain/basal diencephalon are characterized in most of vertebrate groups by their projection to the subpallial and pallial areas of the telencephalon.

In mammals, a majority of the DA cells of A9 (substantia nigra pars compacta, $\mathrm{SNc}$ ) are located in the midbrain, as well as a large part of the A10 neurons (ventral tegmental area, VTA). The A8 group corresponds to the retrorubral component of the DA neurons. Many neurons of the SNc project to the dorsal/somatic striatum in the basal ganglia, controlling mostly sensori-motor programming (nigro-striatal system). In contrast, DA cells in VTA project to areas related to the limbic system such as ventral/visceral basal ganglia (e.g., nucleus accumbens) or amygdala (meso-limbic system), as well as the PFC (meso-cortical system). They play a central role in reward-related behaviors and various cognitive functions such as working memory (Kelley, 2004; Björklund and Dunnett, 2007; Wise, 2009).

Although it may be a too simplified dichotomy (for example some SNc cells also project to the limbic and cortical areas and some VTA cells to the caudate-putamen), the distinct projection pathways to the basal ganglia have been applied to identify the A9 or A10 homologs in the non-mammalian species; DA cell populations projecting to the dorsal striatum were considered to be A9, A10 being those projecting to the ventral striatum (nucleus accumbens). In the avian midbrain, the general configuration is very similar to that of mammals. DA cells providing a massive innervation to the dorsal/somatic striatum are located more dorsolaterally (as is the case in the mammalian $\mathrm{SNc}$ ), while those projecting to the ventral/ visceral striatum are located ventromedially (as the mammalian VTA), and the corresponding regions are now named as $\mathrm{SNc}$ and VTA, respectively (Reiner et al., 2004). Similar cell populations are present in reptilian species (Smeets, 1994; Smeets and Reiner, 1994), and as in mammals they extend from the mesencephalon up to the basal part of the two first prosomeres, at least.

In amphibians as well, similar nigro-striatal and meso-limbic pathways are identified, but unlike amniotes, the DAergic cells of amphibians are shifted more rostrally, many of them being located in the diencephalic territories. Then, the neurons giving rise to the two main projection fibers are intermingled rather than segregated (Marin et al., 1997). Midbrain DA cells with extension into the diencephalic posterior tuberculum are also found in cartilaginous fishes with two different populations. One, named the tegmental area is located just anterior to the interpeduncular nucleus, and the other, a putative substantia nigra, is scattered around the red nucleus (Stuesse et al., 1994).

In contrast, there is no midbrain DA cell in teleosts (Meek, 1994; Rink and Wullimann, 2001), or in lampreys (Pierre et al., 1997; Barreiro-Iglesias et al., 2008). In representatives of this very large group of species (more than 24,000 species), DA neurons are found at three main locations, the periventricular nucleus of the posterior tuberculum, the paraventricular organ, and the posterior tuberal nucleus, all located in the basal area of the third prosomere. It was demonstrated that some of the THir cells in the zebrafish posterior tuberculum (periventricular nucleus of posterior tuberculum; TPp) project to the subpallium, and co-express the transcription factor Nurr1/NR4A2, suggesting the presence of teleost counterpart of A9/A10 cells (Rink and Wullimann, 2001; Blin et al., 2008). However, a recent study of zebrafish larval brains demonstrated that the telencephalic projection from DA cells of the posterior tuberculum is scarce, and that the same TH cell of the posterior tuberculum (TPp, group 4) projects to the diencephalon, hindbrain, and spinal cord in addition to the subpallium, (Tay et al., 2011). These cells depend on the transcription factor Otp, suggesting that they resemble the mammalian A11 [see Diencephalic Cell Groups (A11-A15)]. Whether DA cells of the teleostean posterior tuberculum share also molecular determinants and phenotype with the A9/A10-like cells of mammals, and whether older fish may exhibit more prominent ascending projection from the TPp, await more precise characterization. Currently there is no data on the functional role played by the DA neurons of the posterior tuberculum (or other population of DA neurons) in the basal ganglia circuitry in zebrafish, and it is uncertain if a homolog of A8-A10 exists in teleosts. A mesencephalic component of DA neurons has been described in a non-teleost fish, the gar Lepisosteus osseus, rendering plausible the hypothesis that the lack of DA cells in the mesencephalon could be specific to teleost (Parent and Northcutt, 1982). 
The target area of the A9 DA cells, the dorsal striatum, contains massive THir or DAir terminals, as well as abundant $\mathrm{D}_{1 \mathrm{~A}}$ and $\mathrm{D}_{2}$ receptors in amniotes. In mammals, $\mathrm{D}_{1 \mathrm{~A}}$ receptor tends to be colocalize with substance $\mathrm{P}(\mathrm{SP})$, while $\mathrm{D}_{2}$ receptor co-localize with enkephalin (ENK). Functional and pharmacological studies have suggested that DA stimulates $S P$ cells by $D_{1 A}$ receptors while $D_{2}$ receptors inhibit ENK cells in the striatum, regulating the direct and indirect pathways of the basal ganglia circuitry (Gerfen, 1992). The basal ganglia circuitry for motor output is well studied in birds as well, and known to be essentially similar to that of mammals (Reiner, 2002). Immunohistochemical and hodological studies suggest that amphibians also share the basic basal ganglia organization similar to amniotes (Marin et al., 1998b; Maier et al., 2010). Together with abundant TH terminals (González and Smeets, 1994; Marin et al., 1998a) and $\mathrm{D}_{1 \mathrm{~A}}$ receptors (our unpublished data) in the amphibian striatum, it is likely that the role of DA in the basal ganglia motor control is conserved in tetrapods.

The conservation of meso-limbic systems is less clear. DA input to the nucleus accumbens is critical for reward associated behavior, thus intensively studied in the context of the drug addiction. In mammals, $\mathrm{D}_{3}$ receptor shows particular expression in the island of Calleja and nucleus accumbens (Bouthenet et al., 1991; Landwehrmeyer et al., 1993), while this seems not the case in birds. Based on a study in zebrafinch and chicken (Kubikova et al., 2010), $\mathrm{D}_{3}$ transcripts are weakly expressed rather in the pallial region, with no remarkable expression in the proposed homologous region of the nucleus accumbens (Reiner et al., 2004; Balint and Csillag, 2007). Midbrain DA input to a proposed nucleus accumbens are found in amphibians, but the receptor distribution is not known.

The meso-cortical system is even more difficult to compare among different vertebrate classes, because there was no homolog of the PFC proposed so far outside of mammals. Nonetheless, behavioral, hodological, neurochemical, and electrophysiological studies suggest that birds also possess a pallial association area functionally equivalent to the PFC (Mogensen and Divac, 1982; Güntürkün, 2005). It is located in the caudal part of the avian pallium named the nidopallium caudolateral (NCL). The avian NCL contains relatively high amount of THir fibers and of $\mathrm{D}_{1 \mathrm{~A}}$ receptors as it is also the case in the mammalian PFC. DA depletion or blockade of $\mathrm{D}_{1 \mathrm{~A}}$ receptors interferes with working memory and attention task as shown in mammals (Rose et al., 2010). The similar functional properties of NCL and PFC extend from cellular to behavioral levels (Mogensen and Divac, 1982; Güntürkün, 2005). It is likely to be a consequence of convergent evolution, DA being co-opted in each case to support similar function, raising intriguing questions. At the cellular level, DA is known to increase the firing frequency of preactivated neurons via $\mathrm{D}_{1}$-like receptors in mammals and birds (Güntürkün, 2005). In mammals, $\mathrm{D}_{1 \mathrm{~A}}$ receptor subtype is thought to be involved in this property. However, avians possess another subtype of $\mathrm{D}_{1}$ receptor previously known as $\mathrm{D}_{1 \mathrm{D}}$, and proposed to be a $\mathrm{D}_{1 \mathrm{C}}$ ortholog (see Dopamine Receptors), which is selectively expressed in the pallial areas including NCL (Kubikova et al., 2010). It is thus possible that the $\mathrm{D}_{1 \mathrm{C} / \mathrm{D}}$ subtype, in addition to $\mathrm{D}_{1 \mathrm{~A}}$, plays an important role for cognitive functions in birds. Secondly, the extracellular DA level in the PFC and NCL is higher than in the other dopaminoceptive regions such as the striatum (Sharp et al., 1986; Bast et al., 2002). This may play an important role for a sustained, memory-related activity in these brain areas. In the mammalian PFC, DAT is weakly expressed, and DA is mainly captured by the noradrenaline transporter (NET). Since uptake velocity by NET is not as high as by DAT, it may account for the slow uptake of DA in the PFC. Neither the expression patterns of DAT nor that of NET are known in the avian NCL and this should be interesting to investigate.

\section{DETERMINATION AND DIFFERENTIATION OF THE DOPAMINE NEURON IDENTITY IN THE CENTRAL NERVOUS SYSTEM OF VERTEBRATES \\ A MASTER GENE OF THE DA PHENOTYPE?}

Dopamine neurons of the CNS can be defined as the cells using DA as a neurotransmitter. By this definition, the coincident expression of TH, AADC, vMAT2, and DAT in the same subsets of neurons has been considered to be critical for a functional DA cells, and they are collectively referred to as DA markers. In the model nematode Caenorhabditis elegans, it was recently demonstrated that the genes encoding these DA markers were transcribed upon the action of a common transcription factor, ast-1 (a member of the ETS transcription factor family), which activates a cis-regulatory module found in the sequences of each of the genes encoding the DA components (Flames and Hobert, 2009). Since the same authors showed that, in the mouse olfactory bulb, TH required Etv1/ER81 (also an ETS factor) to be expressed, it was tempting to propose that the expression of the full dopamine phenotype could depend on a "master gene" of the ETS family, controlling late steps of neuronal differentiation and the determination of neurotransmitter identity of neurons. However, it was subsequently shown that, although Etv1/ER81 was able to transactivate the THgene in the mouse olfactory bulb, it was the case neither for the other components of the DA phenotype (AADC, $v M A T 2, D A T)$, nor for TH in other brain areas. In addition, this action of Etv1/ER81 seems to be rather specific to rodents (Cave et al., 2010). Another ETS transcription factor, Etv5/ERM, which had been suggested to regulate the DA phenotype of the VTA/SNc neurons, was demonstrated to be dispensable. Finally, no other ETS-related factors are expressed at the right place to regulate the expression of the DA markers (Wang and Turner, 2010). Thus, except in C. elegans, the notion of a common genetic program governing DA cell differentiation is very unlikely to exist.

\section{GENERAL PRINCIPLES OF DAergic DIFFERENTIATION}

As a matter of fact, the DA systems are very heterogeneous in the vertebrate brain. Detailed studies of the relative distribution of the DA markers in the brain of several vertebrate species have shown that they are not always co-localized in the same cells and that their abundance varies significantly from one brain nuclei to another (Lorang et al., 1994; Mel'nikova et al., 2005; Weihe et al., 2006; Björklund and Dunnett, 2007; Yamamoto et al., 2011); reviewed in Björklund and Dunnett (2007). Thus, the DA neuronal groups differ in their molecular phenotypes as well as in the neurological functions they modulate (Cave and Baker, 2009). Accordingly, the molecular mechanisms and gene networks governing the differentiation of the DA systems are also different.

These mechanisms of differentiation vary depending on the location of the DA progenitors in the regionalized neural tube, in line with the concept of a phylotypic period during the embryonic 
development (Mathis and Nicolas, 2002; Osorio et al., 2010). The regionalization of the neural tube depends on the formation and the positioning of signaling organizing centers, such as the MHB (secreting mostly FGF8), the zona limitans intrathalamica (ZLI, secreting mostly Sonic Hedgehog - Shh), the anterior neural ridge (ANR, secreting mostly FGF8), the notochord and prechordal plate, and the floor plate in the ventral neural tube [secreting mostly BMPs (TGF $\beta$-like factors), Wnts, and Shh], and dorsal midline structures or the roof plate dorsally (secreting mostly BMPs, Wnt, or Wnt inhibitors; Wilson and Houart, 2004; Vieira et al., 2010). These signals are translated into the patterning of antero-posterior, mediolateral, and dorso-ventral morphogenetic units. They are defined as longitudinal columns or plates (floor, basal, alar, and roof plates) and transverse compartments (neuromeres). The neuromeres are named, from posterior to anterior, rhombomeres in the rhombencephalon, then mesencephalon (a neuromere on its own), and prosomeres in the prosencephalon (Puelles, 1995; Vieira et al., 2010). Gene expression is thus controlled in spatially and temporally defined manner, and the combination of genes expressed in each of the neuromere influences the fate and differentiation of neural progenitors and new-born neurons.

The differentiation of all the DA cells takes place anterior to the MHB. This highlights the key role of this structure in the process. Then, DAergic neurogenesis is regulated by distinct genetic networks, depending on the position of the progenitors in the neural tube. Variations around these genetic pathways are certainly at the center of the corresponding disparity of the organization and function of DA cell groups among vertebrate species.

For example, in the olfactory bulb, an anterior telencephalic area, the differentiation of DA neurons depends on the combination of at least three transcription factor encoding-genes, Etv1/ER81, Pax6, and Meis2, as key determinants of the DA phenotypes (Allen et al., 2007). In contrast, the gene networks used for the specification of DA cell groups are very different in the midbrain and diencephalic/ hypothalamic cell groups (Figure 4).

\section{DIFFERENTIATION OF MESENCEPHALO-DIENCEPHALIC DA CELL POPULATION (A8-A10)}

Currently, our knowledge of the differentiation mechanisms of DA neurons mostly comes from mammalian (e.g., mouse) studies on $\mathrm{SNc}$ and VTA, and some works have been done in chick embryos as well (reviewed in Ang, 2006; Prakash and Wurst, 2006; Smidt and Burbach, 2007). Seminal work based on loss- and gain-of-function experiments in the mouse suggested that FGF8 secreted at the MHB and Shh secreted by the ventral structures (the notochord and the prechordal plate) were essential for the differentiation of mesencephalic DA cells (reviewed in Hynes and Rosenthal, 1999). Other signals such as Nodal, Wnt-related factors, or BMPs are also crucial for the regulation of different aspects of the DA differentiation, in a spatially and temporally controlled manner (reviewed in Prakash and Wurst, 2006; Smidt and Burbach, 2007).

In addition, the notochord and the prechordal plate may have different signaling properties (Vieira et al., 2010), which may result in differences in the induction and differentiation of ventral DA progenitors in the mesencephalon vs the ventral part of the three first prosomeres (such as the presence of retinaldehyde dehydrogenase in $\mathrm{p} 1-\mathrm{p} 3$ neurons but not in mesencephalic neurons; Smidt and Burbach, 2007). Variations on this theme may exist from one vertebrate species to another. An extreme case is represented by the teleost fishes, in which no DA cells are found in the ventral mesencephalon nor p1-p2 (see Comparative Anatomy of Dopamine Systems in Vertebrates; Figure 3). Thus, the role of the signaling pathways involved in the determination and differentiation of DA neurons in front of the MHB in teleost fish may be different from that in amniotes. An illustration of this fact is provided by the FGF8 null zebrafish mutant (acerebellar-ace-mutant), which exhibits normal production of DA neuron anterior to the MHB, although the induction of other catecholaminergic neurons posterior to it were strongly affected, as in mammals (locus coeruleus; Holzschuh et al., 2003). The redundancy of FGF signaling is higher in teleost fish (due to an additional gene duplication) than in other species, and the precise role of FGF signaling in the specification of DA progenitors anterior to the MHB remains unclear.

The amniote mesencephalo-diencephalic neurons all derived from the floor plate cells are expressing Shh and FoxA2 (Ono et al., 2007; Bonilla et al., 2008; Lin et al., 2009). In mouse, the Otx1/2 genes and LIM-homeodomain genes $L m \times 1 a / b$, expressed in proliferative ventricular zone, are early determinants of the DA fate (Smidt et al., 2000; Puelles et al., 2004). Lmx1a, by activating Msx1, promotes the expression of the proneural gene Ngn2. This step is important to recruit proliferative progenitors toward a more committed fate also marked by the expression of another proneural gene, Asc-l1 (Mash1; Andersson et al., 2006; Kele et al., 2006). $L m x 1 a$ continues to be expressed in the same progenitors, but it is also expressed (together with $L m x 1 b$ ) in post-mitotic precursors and differentiating DA neurons. Then, the orphan nuclear receptor Nurr1/NR4A2 comes into play into post-mitotic progenitors (Zetterström et al., 1997; Saucedo-Cardenas et al., 1998; Smits et al., 2003), and this factor is crucial for the expression of TH, vMAT2, and DAT (but not AADC; Smits et al., 2003). Ngn2 is transiently expressed in post-mitotic progenitors and involved in the acquisition of generic and subtype specific traits by differentiating DA neurons (Kele et al., 2006). Other parallel pathways such as the Wnt-dependent induction of $\mathrm{Otx2}$ (required to repress $N k \times 2.2$, a determinant of the serotonergic phenotype posterior to the MHB, in the ventral midbrain, Prakash et al., 2006, and for the differentiation of posterior DA progenitors, Omodei et al., 2008), or the FGF8-dependent expression of En1/2 (Simon et al., 2001), as well as the expression of Pitx3 (Asbreuk et al., 2002), are critical for the full differentiation and maintenance of midbrain DA neurons throughout life (reviewed in Prakash and Wurst, 2006; Smidt and Burbach, 2007; and references therein). Differences in expression of molecular markers of SNc and VTA DA cells may depend also on specific transcription factors such as Otx2 (Di Salvio et al., 2010).

This pathway is not fully conserved in non-mammalian species, and especially in teleost fishes that lack the mesencephalic and posterior diencephalic components (prosomeres 1 and 2) of DA cells. In the zebrafish, which has no Ngn2 gene but expresses $N g n 1$ instead, the DA progenitors also express $L m x 1 b$. However, the sequence of expression of the proneural gene Asc-l1 (Zash1a/b), Nurr1/NR4A2, and $T H$ is rather different from that in mammals, the population of progenitors labeled by each of these genes being much more temporally segregated from each other (Ryu et al., 


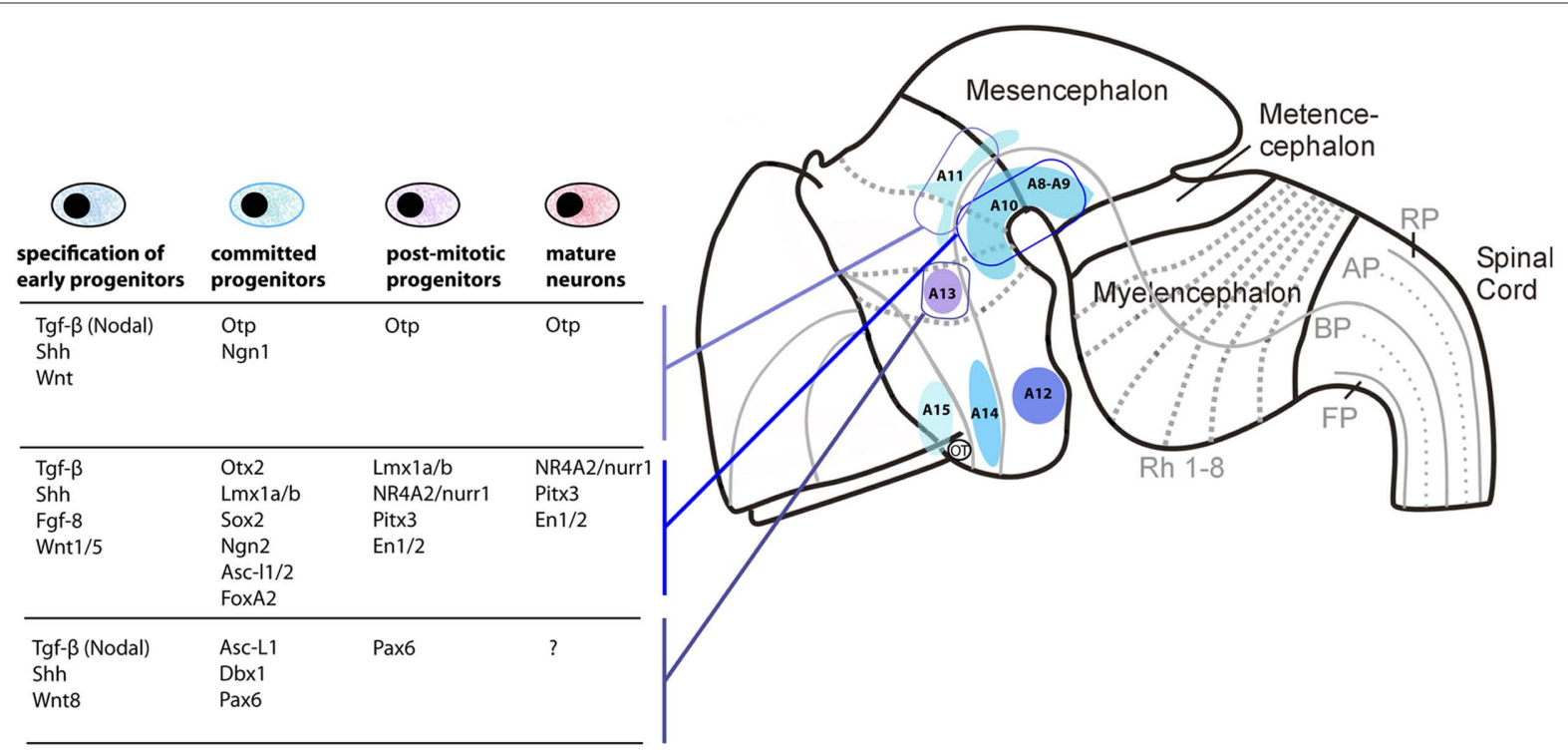

FIGURE 4 | Distinct differentiation pathways for different DA cell groups in mouse. The localization of the main DA-synthesizing nuclei is shown on a neuromeric representation of the mouse embryonic brain. Signaling molecules and genes known to be involved in the differentiation of the A11 (first row) A8A10 DA nuclei (in the midbrain and first basal diencephalic prosomeres; second row) and A13 DA nuclei (in the ventral thalamus; third row) are indicated as a table. Note that DA cells in the three different areas depend on different signaling and transcription factors expression at each step of the cell differentiation, although little is still known in the case of A11 and A13. This observation supports the hypothesis that different DA neuronal systems have been recruited independently, by different transcriptional mechanisms, probably early in vertebrate evolution.
2006; Filippi et al., 2007; Blin et al., 2008). In addition, although $L m \times 1 b$ is necessary for the commitment of early DA progenitors, Pitx3 does not seem to play a role in DA terminal differentiation in zebrafish (Ryu et al., 2006; Filippi et al., 2007).

\section{DIFFERENTIATION OF DIENCEPHALO-HYPOTHALAMIC DA CELL POPULATIONS}

As compared to the diencephalo-mesencephalic A8-A10 neuronal populations, the differentiation mechanisms of the diencephalo-hypothalamic A11-A15 nuclei are far much less known. The factor Shh secreted from the prechordal plate is crucial to specify hypothalamic and retinal territories in mammals marked by the early expression of key-transcription factors such as Six 3 and Rx (reviewed in Wilson and Houart, 2004; Szarek et al., 2010). Later, as shown by experiments made in chick embryos, down-regulation of Shh expression by BMP7 (a TGF- $\beta$ related factor) is crucial to determine the fate of proliferative progenitors in the tubero-mamillary area, and to specify tuberal hypothalamic DA neurons (corresponding to A12; Manning et al., 2006). This may also be true in mammals, since the sequential effect of Shh and BMP7 can induce the hypothalamic DA cell fate in the mouse embryonic stem cellderived neural progenitor cells (Ohyama et al., 2005). Mouse A12 DA neurons also depend on the Achaete-scute-like gene Mash1 at early stages of neurogenesis, but their maintenance requires Mash1 inhibition at later stages (McNay et al., 2006). In the more dorsally located hypothalamus, the role of Otp, Brn2, $\operatorname{Sim} 1 / 2$, and Anrt2 on the specification of neuroendocrine neurons is well studied (Acampora et al., 1999; Michaud et al., 2000; Goshu et al., 2004), however, many of them are not specifically focusing on DA neurons.
Genetic experiments in zebrafish showed that, more than Shh, the Nodal pathway (Nodal is a TGF $\beta$ signaling factor), and the Wnt pathways are critical for differentiation of the ventral progenitors of the diencephalon and hypothalamus from which DA precursors arise (Mathieu et al., 2002; Kapsimali et al., 2004). These signaling pathways are also likely to play a major role in mammals but Nodal mutants are lethal at early stages and thus the effect of this signal has not been demonstrated on hypothalamus specification (reviewed in Szarek et al., 2010). The role of Nodal in the differentiation of diencephalic DA progenitor could be indirect. Indeed, when FoxH1, a Nodal target gene in invalidated (Holzschuh et al., 2003) no DA neurons are found in the ventral diencephalon. However, in a mutant of the Nodal pathway (MZoep, the zebrafish homolog of Cripto a Nodal co-receptor) the rescue of signals emitted by the prechordal mesendoderm (in particular Wnt and Shh signals), permits the specification of DA cell precursors in the diencephalon (Mathieu et al., 2002; reviewed in Schweitzer and Driever, 2009).

Early specification of DA neural progenitors depends at least in part on the Krüppel-like, zinc finger transcription factor Fezf2, which is tightly repressed by the Wnt signals (reviewed in Shimizu and Hibi, 2009). This signaling activity also controls the size of the DA progenitor pool (Russek-Blum et al., 2008). As for the DA precursors of the ventral mesencephalo-diencephalon, proneural genes in the hypothalamus follow a sequence of expression with firstly Ngn2 (or Ngn1 in zebrafish) and then Asc-ll. Ngn expression is controlled by Fezf2 both in zebrafish and mouse (Jeong et al., 2007; Ryu et al., 2007). Fezf2 also controls the formation and differentiation of Dlx1/2-Pax6 expressing neurons of the ventral thalamus (prethalamus; Hirata et al., 2006), which later give rise to the DA neurons of the ventral thalamus (Vitalis et al., 2000; Wullimann and Rink, 2001). 
A major target of Fezf2 is the Otp gene, which specifies various hypothalamic cell populations (Bardet et al., 2008; Wang and Lufkin, 2000), as well as DA cells of the mammalian A11 (Ryu et al., 2007). In zebrafish, loss-of-function of Otp- $a / b$ severely affects the differentiation of most of the diencephalic/hypothalamic DA cell groups (Blechman et al., 2007; Ryu et al., 2007), including posterior tubercular neurons which project to the subpallium (Tay et al., 2011). These Otp-dependent DA cells of zebrafish are also affected by $\operatorname{sim} 1$ or arnt 2 genes, as it is the case for neuroendocrine cells in the mammalian hypothalamus (Löhr et al., 2009; Schweitzer and Driever, 2009).

A lot remains to be done, to understand better the regulatory logic of the expression of the DA phenotypes in the many DA nuclei throughout the forebrain. Nevertheless, based on our current knowledge, the DA nuclei or neurons located in the retina, the olfactory bulb, the hypothalamus, or the mesencephalo-diencephalic areas are each specified and differentiated upon essentially different combination of genes.

\section{DOPAMINE SYSTEMS IN PROTOCHORDATES AND THE ORIGIN OF THE CENTRAL DA SYSTEMS OF VERTEBRATES}

Since many DA cell clusters are well conserved in craniates, the roots of the evolution of the vertebrate DA systems have to be searched outside vertebrates. Previous studies in the two sister groups of non-craniate chordates, i.e., urochordates (ascidians and larvaceans) and cephalochordates (amphioxus), have shown that the two groups exhibit DA-containing cells in their CNS (Moret et al., 2004, 2005b). From a phylogenetical point of view, recent molecular data suggest that tunicates are closer to craniates than amphioxus (Delsuc et al., 2006).

Basically, in ascidians and cephalochordates, the organization of the neural tube along antero-posterior axis is to a certain extent similar to that of vertebrates. In the protochordates, the anterior domain (named the sensory vesicle in ascidia, and the cerebral vesicle in amphioxus) expresses Otx gene as the vertebrate forebrain/ midbrain does. Similarly, a posterior domain and the vertebrate rhombencephalon both express Hox genes (Wada et al., 1998; Holland and Holland, 1999; Ikuta and Saiga, 2007). In vertebrates, the MHB, which is centered on the limit between the Otx and $G b x$ territories, expresses Pax2/5/8 genes, and secretes FGF8. As previously stated [in Differentiation of Mesencephalo-Diencephalic DA Cell Population (A8-A10)], this domain is a major organizing center of the vertebrate brain, and whether there is some equivalent in non-craniate chordates remains debated (Wada et al., 1998; Holland and Holland, 1999; Ikuta and Saiga, 2007; Imai et al., 2009). Although Otx and Gbx expression domains abut in the amphioxus neural tube, there is no evidence for the existence of a MHB signaling center (Moret et al., 2004; Castro et al., 2006). In contrast, it has been recently shown that FGF8 plays a major role as a signaling component at the boundary between the neck and the visceral ganglion of the ascidian CNS. It allows positioning the expression of $\mathrm{Pax} 2 / 5 / 8$ in the neck, just posterior to the Otx-expressing domain of the sensory vesicle (Imai et al., 2009).

Comparison of this general organization of the neural tube between vertebrates and protochordates, together with a careful analysis of the localization of their DA cells provides interesting clues on the ancestral chordate situation. In adult amphioxus, three distinct DA cell populations have been identified. Two of them are in the cerebral vesicle (population 1 and 2) and one in the posterior brain (population 3), being close to 5HT-containing neurons, which is reminiscent of the vertebrate situation. This led to a suggestion that, although amphioxus has no true MHB, the topology and competence of the neural tube to express DA neurons have been conserved in amphioxus (Moret et al., 2004). The antero-dorsal population 1 is located close to photoreceptors, and it sends short projections ventrally to the central canal, in a manner reminiscent of some hypothalamic neurons in vertebrates. The population 2 is located more medially and laterally in the cerebral vesicle, and it sends projections to the posterior brain and the spinal cord. It could play a role in modulating the activity of the motor pattern generator in this animal. The third population is located in the posterior cerebral vesicle, and exhibits similarities with the area postrema of the vertebrate hindbrain.

In ascidians, there is only one population of 8-12 DA-synthesizing cells located on the left side of the postero-ventral wall of the sensory vesicle, adjacent to a group of photoreceptors (Moret et al., 2005b). Based on the expression territories of regulatory genes, it was suggested that these ascidian DAergic cells were located in a region of the ventral sensory vesicle somewhat comparable to the vertebrate hypothalamus (Moret et al., 2005a). These DA-immunoreactive cells express TH and AADC, but $v M A T$ gene expression is undetectable (Moret et al., 2005b; Razy-Krajka et al., unpublished). In addition, they express the membrane transporter SERT, enabling these cells to contain both 5HT and DA (no other member of the MAT are present in the ciona genome). Ciona has also lost $D_{1}$-like or $D_{2}$-like receptor genes, and instead, DA acts via $\alpha_{2}$-like receptors located on DA cells themselves and on some of their probable targets (GABA and glutamate neurons). The very peculiar features of the ascidian DA cells stress the unexpected flexibility or adaptability of the monoamine systems. It may be followed by many gene losses which have taken place in the urochordate lineage, including DA receptor genes and MAT genes (DAT/ $N E T$ ). This flexible property gives robustness and adaptability to the systems as a whole and this would have been beneficial to many species during evolution.

In another respect, new data on the ascidian DA cells suggest that they share many properties found in DAergic amacrine cells in the vertebrate retina (Razy-Krajka et al., unpublished). For example, ascidian DA cells express transcription factors or other markers found both in hypothalamus and retina such as six3/6, meis, pax6, visual cycle proteins. They also express adrenergic receptors, and contact to glutamatergic and GABAergic neurons, as DA amacrine cells do. In addition, behavioral study demonstrated that they modulate swimming behavior in response to light and one of their roles could be to regulate motor behavior prior to metamorphosis. This important observation led to draw the hypothesis that DA cells in the ancestral chordate were located in a photoreceptive territory of the anterior neural tube, which is homologous to both retina and hypothalamic region (Figure 5). These DA cells were probably multifunctional and able to modulate neural functions such as sensory input, motor control, and hormonal regulation.

Together with a better knowledge of the possible evolutionary history of the molecular components of DA neurons, genetic networks controlling DA neuron differentiation, the localization 


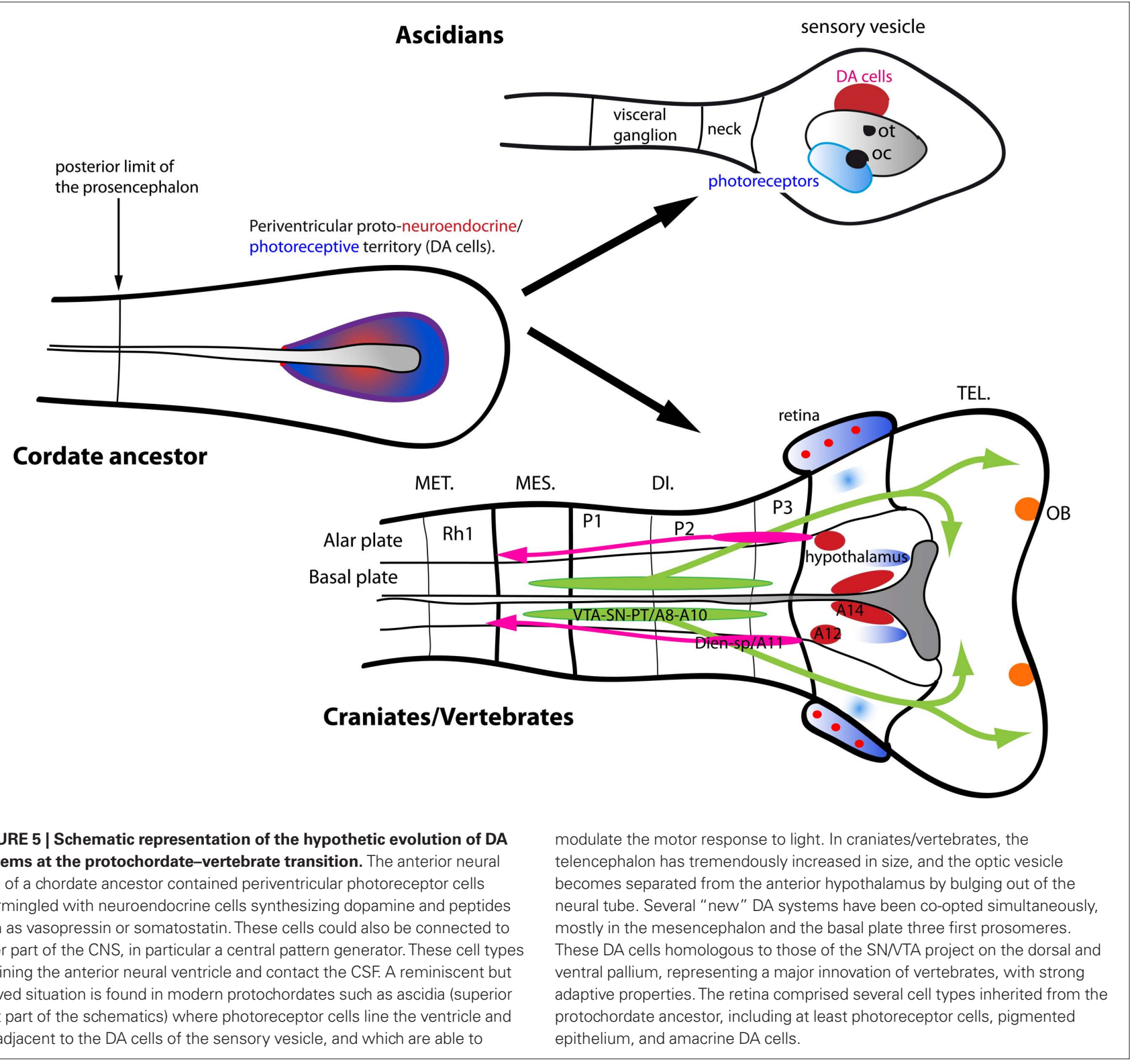

in the brain, and the new data obtained on the protochordate DA systems, we propose renewed hypothesis of the evolution of DA systems in craniates.

\section{HYPOTHESIS ON THE EVOLUTION OF DA SYSTEMS IN CRANIATES/VERTEBRATES}

Dopamine, as a major neuromodulatory transmitter, has certainly played a crucial role in adaptation of animal behavior all along evolution. As described above, the DA phenotype relies on the simultaneous expression of a molecular module consisting of the biosynthetic enzymes TH and AADC, the transporters DAT and vMAT, and the degradation enzymes MAO and COMT. In turn, the action on DA relies on the presence of members of the $\mathrm{D}_{1}$ and $\mathrm{D}_{2}$ classes of receptors on target cells. Many of these operational molecules are present in all bilaterian groups (TH, AADC, vMAT, MAT, $\mathrm{D}_{1}$ and $\mathrm{D}_{2}$ receptors), while others are in chordates only (MAO, and
COMT), as presented in Section "Molecular Components Defining the Phenotype of DA Neurons and their Phylogeny." Thus, all the components of the prototypic DA neurotransmission system found in modern vertebrates were on hand in ancestral chordates. The coordinated cellular expression of these components was mandatory to make a neurotransmission system using DA. It was certainly operant in ancestral chordates also, based on our current knowledge of protochordates. It is however rather difficult to figure out how the ancestral chordate DA system looked like from an anatomical and physiological point of view.

Recent data about the DA systems of ascidia suggest that DA cells of the sensory vesicle on the one hand, and DA cells of the hypothalamus and the retina of vertebrates on the other hand, may have originated from a common neuroendocrine, photoreceptive territory surrounding the ventricle of the neural tube in ancestral chordates (see Section Dopamine Systems in Protochordates and the 
Origin of the Central DA Systems of Vertebrates). This hypothesis is reinforced by the situation of amphioxus DA cells, which are located close to photoreceptors in the wall of the cerebral vesicle (Satir, 2000; Vigh et al., 2002); a region proposed to be homologous to the vertebrate prosencephalon (Holland and Holland, 1999; Kozmik et al., 2007). This contention of an ancestral protohypothalamic area, containing both neuroendocrine cells such as DA cells and photoreceptors, resembles the hypothesis of a primordial photoreceptive neuroepithelium folded into the anterior neural tube of ancestral chordates, initially proposed by F. K. Studnicka in 1898 (Walls, 1942; Lamb et al., 2007). It also fits with the observation that the deep brain photoreceptors (CSF-contacting cells of the hypothalamus) and the photoreceptive organs (retina and pineal organ) are all derived from the ventricle-lining prosencephalon (Vigh et al., 2004; Figure 5). Thus, based on current data, the ancestral DA neuron population of chordates could have been located in a protohypothalamic periventricular area at the anterior part of the neural tube.

The transition between protochordates and craniates corresponds to the emergence of the "new head," to quote Gans and Northcutt (1983). The encephalization, which accompanied the major development of the neural crest, as well as the emergence of the sensory placodes, were major innovations that transformed the probably small and frail last common ancestor of protochordates and craniates into a much more efficient predator. Obviously, the DA neuronal systems may have followed the tremendous expansion of the forebrain in craniates.

In this respect, the emergence of secondary organizers of the neural tube in the head primordium, such as the prechordal plate, $\mathrm{MHB}, \mathrm{ANR}, \mathrm{ZLI}$, and also the cephalic neural crest, have certainly been crucial to promote both the spectacular expansion of the prosencephalon and its regionalization (prosomeres). Thus, under the influence of these new signaling networks of the head, regulatory elements of the genes encoding the components of the DA markers should have been co-opted and selected for their expression in permissive, competent territories of the forebrain. The occurrence of duplication of a majority of the molecular components of the DA phenotype, as a part of large genome duplications that took place early in craniate evolution, gave the genes the opportunity to acquire new expression territories. This is particularly the case for TH, vMAT, or DAT/NET transporter (see Molecular Components Defining the Phenotype of DA Neurons and their Phylogeny).

In the framework of this hypothesis, the retinal and hypothalamic DA populations in modern vertebrates are the direct descendants of the putative protohypothalamic DA cells of the ancestral chordate. These cells have undergone segregation and parcelation from ancestral retino-hypothalamic primordium. The role of the Shh signaling pathway in the formation of the retina and hypothalamus is well known, and it is possible that its timely secretion from the prechordal plate, together with the action of Nodal-induced pathways (an other invention of craniates) was a key-event in the dorso-ventral patterning of early craniates, which accompanied the formation of the "new head-new brain." During the early development of the vertebrate neural tube, Nodal and Shh signals are necessary for the future retina to protrude out of the secondary prosencephalon simultaneously with a movement of subduction of the hypothalamus, which pulls apart the two territories (England et al., 2006; Stigloher et al., 2006). In addition, early regionalization of the hypothalamus is still dependent on the Nodal and Shh signals together with the action of Wnts and BMPs. This regionalization probably facilitated the segregation of different DA populations in antero-dorsal (A14,A15 for example) and postero-ventral domains (A12 for example) of the hypothalamus.

Dopamine cell populations have also been recruited in other regions, due to the signaling innovations that pattern the craniate/ vertebrate neural tube. The DA population of the olfactory bulb derives from the anterior periventricular area (e.g., the subventricular zone of mammals) and its migratory property was probably secondarily acquired in the earliest craniates. The ventral thalamic population (A13, zona incerta in mammals) and the pretectal DA population are also probably ancestral features of craniates, and represent the most prominent components of the alar domain of the diencephalon.

One of the major innovations among the DA systems of craniates would be the emergence of the DA system of the ventral plate of p1-p2-p3 and ventral mesencephalon (nigro-striato-cortical systems of amniotes, A8-A10). Whether this system was modified from pre-existing hypothalamic DA neurons or it was a true innovation depending on the emergence of the MHB and its signaling properties remains impossible to decipher based on current data. A distinct characteristic of this system is ascending projections to the telencephalon. This allowed DA to act on the newly developed neural area, which took a huge expansion in vertebrates, particularly in amniotes.

As previously stated (Kapsimali et al., 2003), the basic role of DA systems has not significantly changed during vertebrate evolution, as far as the molecular and cellular mechanisms are concerned. None the less, DA modulates sensory information in the retina or the olfactory bulb, regulates many neuroendocrine functions of hypothalamic areas, and controls sensori-motor programming, emotions, motivation, and memory in the telencephalic areas. It is due to the anatomical variations in the craniates/vertebrates accompanied by the quantitative changes of the organization of the CNS. For example, the expansion of the telencephalon and its connectivity with different brain areas determines how sensory perception and motor action are elaborated and how they are used for the adaptation of the life style of animals to their environment. The duplication of genes encoding the molecular components of DA systems, together with the "flexible" use corresponding to the molecular context (see Molecular Components Defining the Phenotype of DA Neurons and their Phylogeny), allowed a large degree of plasticity to the craniate DA systems. The parallel advance of our knowledge on the molecular diversity and on the ontogeny of DA cells in protochordates and vertebrates led to a broader and more precise view of the evolution of DA systems. A better understanding of the physiology and pathology of DA systems is anticipated from such a comparative approach.

\section{ACKNOWLEDGMENTS}

Profound thanks to Dr. F. Razy-Krajka, for his advices and discussion on the topic. We also thank Dr. V.V. Gurchenkov for his critical reading of the manuscript and his help with Figure 3. Work in our laboratory is supported by grants from the CNRS and Université Paris-Sud, the Agence Nationale de la Recherche and Fondation de France. Kei Yamamoto was supported by ANR and the Région Île-de-France. 


\section{REFERENCES}

Acampora, D., Postiglione, M. P., Avantaggiato, V., Di Bonito, M., Vaccarino, F. M., Michaud, J., and Simeone, A. (1999). Progressive impairment of developing neuroendocrine cell lineages in the hypothalamus of mice lacking the Orthopedia gene. Genes Dev. 13, 2787-2800.

Agathocleous, M., and Harris, W. A. (2009). From progenitors to differentiated cells in the vertebrate retina. Annu. Rev. Cell Dev. Biol. 25, 45-69.

Aguayo, L. G., and Grossie, J. (1994). Dopamine inhibits a sustained calcium current through activation of alpha adrenergic receptors and a GTP-binding protein in adult rat sympathetic neurons. J. Pharmacol. Exp. Ther. 269, 503-508.

Allen, Z. J. N., Waclaw, R. R., Colbert, M. C., and Campbell, K. (2007). Molecular identity of olfactory bulb interneurons: transcriptional codes of periglomerular neuron subtypes. J. Mol. Histol. 38, 517-525.

Andersson, E., Jensen, J. B., Parmar, M., Guillemot, F., and Bjorklund, A. (2006). Development of the mesencephalic dopaminergic neuron system is compromised in the absence of neurogenin 2. Development 133, 507-516.

Ang, S. L. (2006). Transcriptional control of midbrain dopaminergic neuron development. Development 133, 3499-3506.

Anichtchik, O., Sallinen, V., Peitsaro, N., and Panula, P. (2006). Distinct structure and activity of monoamine oxidase in the brain of zebrafish (Danio rerio). J. Comp. Neurol. 498, 593-610.

Apparsundaram, S., Moore, K. R., Malone, M. D., Hartzell, H. C., and Blakely, R. D. (1997). Molecular cloning and characterization of an L-epinephrine transporter from sympathetic ganglia of the bullfrog, Rana catesbiana. J. Neurosci. 17, 2691-2702.

Asbreuk, C. H. J., Vogelaar, C. F., Hellemons, A., Smidt, M. P., and Burbach, J. P. H. (2002). CNS expression pattern of Lmxlb and coexpression with Ptx genes suggest functional cooperativity in the development of forebrain motor control systems. Mol. Cell. Neurosci. 21, 410-420.

Balint, E., and Csillag, A. (2007). Nucleus accumbens subregions: hodological and immunohistochemical study in the domestic chick (Gallus domesticus). Cell Tissue Res. 327, 221-230.

Bardet, S. M., Martinez-de-la-Torre, M., Northcutt, R. G., Rubenstein, J. L., and Puelles, L. (2008). Conserved pattern of OTP-positive cells in the paraventricular nucleus and other hypothalamic sites of tetrapods. Brain Res. Bull. 75, 231-235.
Barreiro-Iglesias, A., Laramore, C. Shifman, M. I., Anadón, R., Selzer, M. E., and Rodicio, M. C. (2010). The sea lamprey tyrosine hydroxylase: cDNA cloning and in situ hybridization study in the brain. Neuroscience 168, 659-669.

Barreiro-Iglesias, A., Villar-Cervino, V., Anadon, R., and Rodicio, M. C. (2008). Descending brain-spinal cord projections in a primitive vertebrate, the lamprey: cerebrospinal fluid-contacting and dopaminergic neurons. J. Comp. Neurol. 511, 711-723.

Bast, T., Diekamp, B., Thiel, C., Schwarting, R. K., and Gunturkun, O. (2002). Functional aspects of dopamine metabolism in the putative prefrontal cortex analogue and striatum of pigeons (Columba livia). J. Comp. Neurol. 446, 58-67.

Becker, T., Wullimann, M. F., Becker, C. G., Bernhardt, R. R., and Schachner, M. (1997). Axonal regrowth after spinal cord transection in adult zebrafish. $J$. Comp. Neurol. 377, 577-595.

Ben-Jonathan, N., and Hnasko, R. (2001). Dopamine as a prolactin (PRL) inhibitor. Endocr. Rev. 22, 724-763.

Björklund, A., and Dunnett, S. B. (2007). Dopamine neuron systems in the brain: an update. Trends Neurosci. 30, 194-202.

Björklund, A., and Lindvall, O. (1984). "Dopamine-containing systems in the CNS," in Classical Transmitters in the CNS, Part I, Handbook of Chemical Neuroanatomy, Vol.2, eds A. Björklund and T. Hökfelt (Amsterdam: Elsevier), 55-122.

Blechman, J., Borodovsky, N., Eisenberg, M., Nabel-Rosen, H., Grimm, J., and Levkowitz, G. (2007). Specification of hypothalamic neurons by dual regulation of the homeodomain protein Orthopedia. Development 134, 4417-4426.

Blin, M., Norton, W., Bally-Cuif, L., and Vernier, P. (2008). NR4A2 controls the differentiation of selective dopaminergic nuclei in the zebrafish brain. Mol. Cell. Neurosci. 39, 592-604.

Bonilla, S., Hall, A. C., Pinto, L., Attardo, A., Gotz, M., Huttner, W. B., and Arenas, E. (2008). Identification of midbrain floor plate radial glia-like cells as dopaminergic progenitors. Glia 56, 809-820.

Bouthenet, M. L., Souil, E., Martres, M. P., Sokoloff, P., Giros, B., and Schwartz, J. C. (1991). Localization of dopamine D3 receptor mRNA in the rat brain using in situ hybridization histochemistry: comparison with dopamine D2 receptor mRNA. Brain Res. 564, 203-219.

Burman, C., Reale, V., Srivastava, D. P., and Evans, P. D. (2009). Identification and characterization of a novel amphioxus dopamine D-like receptor. $J$. Neurochem. 111, 26-36.

Busby, E. R., Roch, G. J., and Sherwood, N. M. (2010). "Endocrinology of zebrafish: a small fish with a large gene pool," in Zebrafish, eds S. F. Perry, M. Ekker, A. P. Farrell, and C. J. Brauner (London: Academic Press), 173-247.

Callier, S., Snapyan, M., Le Crom, S., Prou, D., Vincent, J. D., and Vernier, P. (2003). Evolution and cell biology of dopamine receptors in vertebrates. Biol. Cell 95, 489-502.

Candy, J., and Collet, C. (2005). Two tyrosine hydroxylase genes in teleosts. Biochim. Biophys. Acta 1727, 35-44.

Carboni, E., and Silvagni, A. (2004). Dopamine reuptake by norepinephrine neurons: exception or rule? Crit. Rev. Neurobiol. 16, 121-128.

Carlberg, M., and Anctil, M. (1993). Biogenic amines in coelenterates. Comp. Biochem. Physiol. C Comp. Pharmacol. Toxicol. 106, 1-9.

Carlsson, A., Lindqvist, M., Magnusson, T., and Waldeck, B. (1958). On the presence of 3-hydroxytyramine in brain. Science 127, 471.

Castro, L. F., Rasmussen, S. L., Holland P. W., Holland, N. D., and Holland, L. Z. (2006). A Gbx homeobox gene in amphioxus: insights into ancestry of the ANTP class and evolution of the midbrain/hindbrain boundary. Dev Biol. 295, 40-51.

Cave, J. W., Akiba, Y., Banerjee, K., Bhosle, S., Berlin, R., and Baker, H. (2010). Differential regulation of dopaminergic gene expression by Er81. J. Neurosci. 30, 4717-4724.

Cave, J. W., and Baker, H. (2009). Dopamine systems in the forebrain. Adv. Exp. Med. Biol. 651, 15-35.

Caveney, S., Cladman, W., Verellen, L., and Donly, C. (2006). Ancestry of neuronal monoamine transporters in the Metazoa. J. Exp. Biol. 209, 4858-4868.

Cornil, C. A., and Ball, G. F. (2008) Interplay among catecholamine systems: dopamine binds to alpha2adrenergic receptors in birds and mammals. J. Comp. Neurol. 511 , 610-627.

Cornil, C. A., Dejace, C., Ball, G. F., and Balthazart, J. (2005). Dopamine modulates male sexual behavior in Japanese quail in part via actions on noradrenergic receptors. Behav. Brain Res. 163, 42-57.

Dahlstrom, A., and Fuxe, K. (1964) Evidence for the existence of monoamine-containing neurons in the central nervous systems. I. Demonstration of monoamines in the cell bodies of brain stem neurons. Acta Physiol. Scand. 62, 1-55.

Daws, L. C., Toney, G. M., Gerhardt, G. A., and Frazer, A. (1998). In vivo chronoamperometric measures of extracellular serotonin clearance in rat dorsal hippocampus: contribution of serotonin and norepinephrine transporters. J. Pharmacol. Exp. Ther. 286, 967-976.

Delsuc, F., Brinkmann, H., Chourrout, D., and Philippe, H. (2006). Tunicates and not cephalochordates are the closest living relatives of vertebrates. Nature 439, 965-968.

Demchyshyn, L. L., Sugamori, K. S., Lee, F. J.,Hamadanizadeh,S.A., and Niznik, H. B. (1995). The dopamine D1D receptor. Cloning and characterization of three pharmacologically distinct D1-like receptors from Gallus domesticus. J. Biol. Chem. 270, 4005-4012.

Di Salvio, M., Di Giovannantonio, L. G., Acampora, D., Prosperi, R., Omodei, D., Prakash, N., Wurst, W., and Simeone, A. (2010). Otx2 controls neuron subtype identity in ventral tegmental area and antagonizes vulnerability to MPTP. Nat. Neurosci. 13 , 1481-1148.

Dubach, M. (1994). "Telencephalic dopamine cells in monkeys, humans, and rats," in Phylogeny and Development of Catecholamine Systems in the CNS of Vertebrates, eds W. J. A. J. Smeets and A. Reiner (Cambridge: Cambridge University Press), 21-47.

Dufour, S., Sebert, M. E., Weltzien, F. A., Rousseau, K., and Pasqualini, C. (2010). Neuroendocrine control by dopamine of teleost reproduction. J. Fish Biol. 76, 129-160.

Dufour, S., Weltzien, F. A., Sebert, M. E., Le Belle, N., Vidal, B., Vernier, P., and Pasqualini, C. (2005). Dopaminergic inhibition of reproduction in teleost fishes: ecophysiological and evolutionary implications. Ann. N. Y. Acad. Sci. 1040, 9-21.

Dunkley, P. R., Bobrovskaya, L., Graham, M. E., von Nagy-Felsobuki, E. I., and Dickson, P. W. (2004). Tyrosine hydroxylase phosphorylation: regulation and consequences. J. Neurochem. 91, 1025-1043.

Eiden, L. E., Schafer, M. K., Weihe, E., and Schutz, B. (2004). The vesicular amine transporter family (SLC18): amine/proton antiporters required for vesicular accumulation and regulated exocytotic secretion of monoamines and acetylcholine. Pflugers Arch. 447, 636-640.

Eisenhofer, G., Kopin, I. J., and Goldstein, D. S. (1985). Catecholamine metabolism: a contemporary view with implication for physiology and medicine. Science 230, 181-183.

England,S.J., Blanchard, G.B., Mahadevan, L., and Adams, R. J. (2006). A dynamic fate map of the forebrain shows how vertebrate eyes form and explains two 
causes of cyclopia. Development 133, 4613-4617.

Fedorow, H., Tribl, F., Halliday, G., Gerlach, M., Riederer, P., and Double, K. L. (2005). Neuromelanin in human dopamine neurons: comparison with peripheral melanins and relevance to Parkinson's disease. Prog. Neurobiol. $75,109-124$.

Filippi, A., Durr, K., Ryu, S., Willaredt, M., Holzschuh, J., and Driever, W. (2007). Expression and function of nr4a2, lmx1b, and pitx3 in zebrafish dopaminergic and noradrenergic neuronal development. BMC Dev. Biol. 7, 135. doi: 10.1186/1471-213X-7-135

Flames, N., and Hobert, O. (2009). Gene regulatory logic of dopamine neuron differentiation. Nature 458, 885-889.

Gans, C., and Northcutt, R. G. (1983). Neural crest and the origin of vertebrates: a new head. Science 220, 268-273.

Garcia-Tornadu, I., Risso, G., PerezMillan, M. I., Noain, D., DiazTorga, G., Low, M. J., Rubinstein, M., and Becu-Villalobos, D. (2010). Neurotransmitter modulation of the GHRH-GH axis. Front. Horm. Res. 38, 59-69.

Gaspar, P., Berger, B., Febvret, A., Vigny, A., Krieger-Poulet, M., and BorriVoltattorni, C. (1987). Tyrosine hydroxylase-immunoreactive neurons in the human cerebral cortex: a novel catecholaminergic group? Neurosci. Lett. 80, 257-262.

Gerfen, C. R. (1992). The neostriatal mosaic: multiple levels of compartmental organization in the basal ganglia. Annu. Rev. Neurosci. 15, 285-320.

González,A., and Smeets, W. J.A. J. (1994). "Catecholamine systems in the CNS of amphibians," in Phylogeny and Development of Catecholamine Systems in the CNS of Vertebrates, eds W. J. A. J. Smeets and A. Reiner (Cambridge: Cambridge University Press), 21-47.

Goodwill, K. E., Sabatier, C., Marks, C., Raag, R., Fitzpatrick, P. F., and Stevens, R. C. (1997). Crystal structure of tyrosine hydroxylase at $2.3 \mathrm{~A}$ and its implications for inherited neurodegenerative diseases. Nat. Struct. Biol. 4, 578-585.

Goshu, E., Jin, H., Lovejoy, J., Marion, J. F., Michaud, J. L., and Fan, C. M. (2004). Sim 2 contributes to neuroendocrine hormone gene expression in the anterior hypothalamus. Mol. Endocrinol. $18,1251-1262$

Guillot, T. S., and Miller, G. W. (2009). Protective actions of the vesicular monoamine transporter 2 (VMAT2) in monoaminergic neurons. Mol. Neurobiol. 39, 149-170.

Güntürkün, O. (2005). Avian and mammalian "prefrontal cortices": limited degrees of freedom in the evolution of the neural mechanisms of goal-state maintenance. Brain Res. Bull. 66, 311-316.

Hirano, J., Archer, S. N., and Djamgoz, M. B. (1998). Dopamine receptor subtypes expressed in vertebrate (carp and eel) retinae: cloning, sequencing and comparison of five D1-like and three D2-like receptors. Recept. Channels 5, 387-404.

Hirata, T., Nakazawa, M., Muraoka, O. Nakayama, R., Suda, Y., and Hibi, M. (2006). Zinc-finger genes Fez and Fez-like function in the establishment of diencephalon subdivisions. Development 133, 3993-4004.

Hökfelt, T., Martensson, R., Björklund, A., Kleinau, S., and Goldstein, M. (1984). "Distributional maps of tyrosine-hydroxylase-immunoreactive neurons in the rat brain," in Classical Transmitters in the CNS, Part I, Handbook of Chemical Neuroanatomy, Vol. 2, eds A. Björklund and T. Hökfelt (Amsterdam: Elsevier), 277-379.

Holland, L. Z., and Holland, N. D. (1999). Chordate origins of the vertebrate central nervous system. Curr. Opin. Neurobiol. 9, 596-602.

Holmberg, K. (1970). The hagfish retina: fine structure of retinal cells in Myxine glutinosa, L., with special reference to receptor and epithelial cells. Z. Zellforsch. Mikrosk. Anat. 111, 519-538.

Holzschuh, J., Hauptmann, G., and Driever, W. (2003). Genetic analysis of the roles of Hh, FGF8, and nodal signaling during catecholaminergic system development in the zebrafish brain. J. Neurosci. 23, 5507-5519.

Hornykiewicz, O. (1962). Dopamine (3-hydroxytyramine) in the central nervous system and its relation to the Parkinson syndrome in man. Dtsch. Med. Wochenschr. 87, 1807-1810.

Huang, S., and Moody, S. A. (1998). Dual expression of GABA or serotonin and dopamine in Xenopus amacrine cells is transient and may be regulated by laminar cues. Vis. Neurosci. 15, 969-977.

Hynes, M., and Rosenthal, A. (1999). Specification of dopaminergic and serotonergic neurons in the vertebrate CNS. Curr. Opin. Neurobiol. 9, 26-36.

Ikuta, T., and Saiga, H. (2007). Dynamic change in the expression of developmental genes in the ascidian central nervous system: revisit to the tripartite model and the origin of the midbrainhindbrain boundary region. Dev. Biol. 312, 631-643.

Imai, K. S., Stolfi, A., Levine, M., and Satou, Y. (2009). Gene regulatory networks underlying the compartmentalization of the Ciona central nervous system. Development 136, 285-293.

Inagaki, S., Shiosaka, S., Takatsuki, K., Sakanaka, M., Takagi, H., Senba, E., Matsuzaki, T., and Tohyama, M. (1981). Distribution of somatostatin in the frog brain, Rana catesbeiana, in relation to location of catecholaminecontaining neuron system. J. Comp. Neurol. 202, 89-101.

Jeong, J. Y., Einhorn, Z., Mathur, P., Chen, L., Lee, S., Kawakami, K., and Guo, S. (2007). Patterning the zebrafish diencephalon by the conserved zincfinger protein Fezl. Development 134, 127-136.

Kah, O., Chambolle, P., Thibault, J., and Geffard, M. (1984). Existence of dopaminergic neurons in the preoptic region of the goldfish. Neurosci. Lett. 48, 293-298.

Kannari, K., Shen, H., Arai, A., Tomiyama, M., and Baba, M. (2006). Reuptake of L-DOPA-derived extracellular dopamine in the striatum with dopaminergic denervation via serotonin transporters. Neurosci. Lett. 402 , 62-65.

Kapsimali, M., Caneparo, L., Houart, C. and Wilson, S. W. (2004). Inhibition of Wnt/Axin/beta-catenin pathway activity promotes ventral CNS midline tissue to adopt hypothalamic rather than floorplate identity. Development 131, 5923-5933.

Kapsimali, M., Le Crom, S., and Vernier, P. (2003). "A natural history of vertebrate dopamine receptors," in Dopamine Receptors and Transporters, eds M. Laruelle, A. Sidhu, and P.Vernier (New York: Marcel Dekker Inc.), 1-43.

Kele, J., Simplicio, N., Ferri, A. L., Mira, H. Guillemot, F., Arenas, E., and Ang, S. L. (2006). Neurogenin 2 is required for the development of ventral midbrain dopaminergic neurons. Development 133, 495-505.

Kelley, A. E. (2004). Memory and addiction: shared neural circuitry and molecular mechanisms. Neuron 44 161-179.

Kiss, J. Z., and Peczely, P. (1987) Distribution of tyrosine-hydroxylase (TH)-immunoreactive neurons in the diencephalon of the pigeon (Columba livia domestica). J. Comp. Neurol. 257, 333-346.

Kozmik, Z., Holland, N. D., Kreslova, J., Oliveri, D., Schubert, M., Jonasova, K. Holland, L. Z., Pestarino, M., Benes, V., and Candiani, S. (2007). Pax-SixEya-Dach network during amphioxus development: conservation in vitro but context specificity in vivo. Dev. Biol. 306, 143-159.

Kubikova, L., Wada, K., and Jarvis, E. D. (2010). Dopamine receptors in a songbird brain. J. Comp. Neurol. 518 741-769.

Kumer, S. C., and Vrana, K. E. (1996). Intricate regulation of tyrosine hydroxylase activity and gene expression. J. Neurochem. 67, 443-462.

Lamb, T. D., Collin, S. P., and Pugh, E. N. Jr. (2007). Evolution of the vertebrate eye: opsins, photoreceptors, retina and eye cup. Nat. Rev. Neurosci. 8, 960-976.

Lanau, F., Zenner, M. T., Civelli, O., and Hartman, D. S. (1997). Epinephrine and norepinephrine act as potent agonists at the recombinant human dopamine D4 receptor. J. Neurochem. $68,804-812$.

Landwehrmeyer, B., Mengod, G., and Palacios, J. M. (1993). Differential visualization of dopamine $\mathrm{D} 2$ and $\mathrm{D} 3$ receptor sites in rat brain. A comparative study using in situ hybridization histochemistry and ligand binding autoradiography. Eur. J. Neurosci. 5, 145-153.

Lazarini, F., and Lledo, P. M. (2011). Is adult neurogenesis essential for olfaction? Trends Neurosci. 34, 20-30.

Le Crom, S., Kapsimali, M., Barome, P. O., and Vernier, P. (2003). Dopamine receptors for every species: gene duplications and functional diversification in Craniates. J. Struct. Funct. Genomics 3, 161-176.

Lee, T. L., Hsu, C. T., Yen, S. T., Lai, C. W. and Cheng, J. T. (1998). Activation of beta3-adrenoceptors by exogenous dopamine to lower glucose uptake into rat adipocytes. J. Auton. Nerv. Syst. 74, 86-90.

Lin, W., Metzakopian, E., Mavromatakis, Y.E., Gao, N., Balaskas, N., Sasaki, H., Briscoe, J., Whitsett, J. A., Goulding, M., Kaestner, K. H., and Ang, S. L. (2009). Foxa1 and Foxa2 function both upstream of and cooperatively with Lmxla and Lmxlb in a feedforward loop promoting mesodiencephalic dopaminergic neuron development. Dev. Biol. 333 , 386-396.

Liu, N. A., Liu, Q., Wawrowsky, K., Yang, Z., Lin, S., and Melmed, S. (2006). Prolactin receptor signaling mediates the osmotic response of embryonic zebrafish lactotrophs. Mol. Endocrinol. 20, 871-880.

Löhr, H., Ryu, S., and Driever, W. (2009). Zebrafish diencephalic A11-related dopaminergic neurons share a conserved transcriptional network with neuroendocrine cell lineages. Development 136, 1007-1017.

Lorang, D., Amara, S. G., and Simerly, R. B. (1994). Cell-type-specific expression of catecholamine transporters in the rat brain. J. Neurosci. 14, 4903-4914.

MacHeroux, P., Seth, O., Bollschweiler, C., Schwarz, M., Kurfurst, M., Au, L C., and Ghisla, S. (2001). L-aminoacid oxidase from the Malayan pit viper Calloselasma rhodostoma. Comparative sequence analysis and characterization of active and inactive forms of the enzyme. Eur. J. Biochem. $268,1679-1686$

Maier, S., Walkowiak, W., Luksch, H., and Endepols, H. (2010). An indirect basal 
ganglia pathway in anuran amphibians? J. Chem. Neuroanat. 40, 21-35.

Manning, L., Ohyama, K., Saeger, B., Hatano, O., Wilson, S. A., Logan, M., and Placzek, M. (2006). Regional morphogenesis in the hypothalamus: a BMP-Tbx2 pathway coordinates fate and proliferation through Shh downregulation. Dev. Cell 11, 873-885.

Marin, O., Smeets, W. J.A. J., and Gonzalez, A. (1997). Basal ganglia organization in amphibians: catecholaminergic innervation of the striatum and the nucleus accumbens. J. Comp. Neurol. 378, 50-69.

Marin, O., Smeets, W. J., and Gonzalez, A. (1998a). Evolution of the basal ganglia in tetrapods: a new perspective based on recent studies in amphibians. Trends Neurosci. 21, 487-494.

Marin, O., Smeets, W. J., and Gonzalez, A. (1998b). Basal ganglia organization in amphibians: chemoarchitecture. J. Comp. Neurol. 392, 285-312.

Masland, R. H. (2001). The fundamental plan of the retina. Nat. Neurosci. $4,877-886$.

Mathieu, J., Barth, A., Rosa, F. M., Wilson, S. W., and Peyrieras, N. (2002). Distinct and cooperative roles for Nodal and Hedgehog signals during hypothalamic development. Development 129, 3055-3065.

Mathis, L., and Nicolas, J. F. (2002). Cellular patterning of the vertebrate embryo. Trends Genet. 18, 627-635.

McNay, D. E., Pelling, M., Claxton, S., Guillemot, F., and Ang, S. L. (2006). Mash1 is required for generic and subtype differentiation of hypothalamic neuroendocrine cells. Mol. Endocrinol. 20, 1623-1632.

Medina, L. (2008). “Evolution and embryological development of forebrain," in Encyclopedic Reference of Neuroscience, eds M. D. Binder and N. Hirokawa (Berlin: Springer-Verlag), 1172-1192.

Medina, L., Puelles, L., and Smeets, W. J. (1994). Development of catecholamine systems in the brain of the lizard Gallotia galloti. J. Comp. Neurol. 350, 41-62.

Meek, J. (1994). "Catecholamines in the brain of Osteichthyes (bony fishes)," in Phylogeny and Development of Catecholamine Systems in the CNS of Vertebrates, eds W. J. A. J. Smeets and A. Reiner (Cambridge: Cambridge University Press), 21-47.

Meister, B., Hokfelt, T., Brown, J., Joh, T., and Goldstein, M. (1987). Dopaminergic cells in the caudal A13 cell group express somatostatin-like immunoreactivity. Exp. Brain Res. 67, 441-444.

Mel'nikova, V. I., Lavrent'eva, A. V., Kudrin, V. S., Raevskii, K. S., and Ugryumov, M. V. (2005). Dopamine synthesis by non-dopaminergic neu- rons in the arcuate nucleus of rat fetuses. Neurosci. Behav. Physiol. 35, 809-813.

Michaud, J. L., DeRossi, C., May, N. R., Holdener, B. C., and Fan, C.M. (2000). ARNT2 acts as the dimerization partner of SIM1 for the development of the hypothalamus. Mech. Dev. 90, 253-261.

Missale, C., Nash, S. R., Robinson, S. W., Jaber, M., and Caron, M. G. (1998). Dopamine receptors: from structure to function. Physiol. Rev. 78, 189-225.

Mogensen, J., and Divac, I. (1982). The prefrontal 'cortex' in the pigeon. Behavioral evidence. Brain Behav. Evol. 21, 60-66.

Moret, F., Christiaen, L., Deyts, C., Blin, M., Vernier, P., and Joly, J.-S. (2005a). Regulatory gene expressions in the ascidian ventral sensory vesicle: evolutionary relationships with the vertebrate hypothalamus. Dev. Biol. 277, 557-566.

Moret, F., Christiaen, L., Deyts, C., Blin, M., Joly, J.-S., and Vernier, P. (2005b). The dopamine-synthesizing cells of the sensory vesicle of the tunicate Ciona intestinalis are located only in a hypothalamus-related domain: implications for the origin of vertebrate catecholamine systems. Eur. J. Neurosci. 21, 3043-3055.

Moret, F., Guilland, J. C., Coudouel, S., Rochette, L., and Vernier, P. (2004). Distribution of tyrosine hydroxylase, dopamine, and serotonin in the central nervous system of amphioxus (Branchiostoma lanceolatum): implications for the evolution of catecholamine systems in vertebrates. J. Comp. Neurol. 468, 135-150.

Moron, J. A., Brockington, A., Wise, R. A., Rocha, B. A., and Hope, B. T. (2002). Dopamine uptake through the norepinephrine transporter in brain regions with low levels of the dopamine transporter: evidence from knock-out mouse lines. J. Neurosci.22, 389-395.

Mossner, R., Simantov, R., Marx,A., Lesch, K.P., and Seif, I. (2006). Aberrant accumulation of serotonin in dopaminergic neurons. Neurosci. Lett. 401, 49-54.

Nagatsu, T. (2004). Progress in monoamine oxidase (MAO) research in relation to genetic engineering. Neurotoxicology 25, 11-20.

Nakashima, A., Hayashi, N., Kaneko, Y. S., Mori, K., Sabban, E. L., Nagatsu, T., and Ota, A. (2009). Role of $\mathrm{N}$-terminus of tyrosine hydroxylase in the biosynthesis of catecholamines. J. Neural Transm. 116, 1355-1362.

Neves, S. R., Ram, P. T., and Iyengar, R. (2002). G protein pathways. Science 296, 1636-1639.

Newman-Tancredi,A., Audinot-Bouchez, V., Gobert, A., and Millan, M. J. (1997).
Noradrenaline and adrenaline are high affinity agonists at dopamine D4 receptors. Eur. J. Pharmacol. 319 379-383.

Obeso, J. A., Rodriguez-Oroz, M. C. Goetz, C. G., Marin, C., Kordower, J. H., Rodriguez, M., Hirsch, E. C., Farrer, M., Schapira, A. H., and Halliday, G. (2010). Missing pieces in the Parkinson's disease puzzle. Nat. Med. 16, 653-661.

Ohyama, K., Ellis, P., Kimura, S., and Placzek, M. (2005). Directed differentiation of neural cells to hypothalamic dopaminergic neurons. Development 132, 5185-5197.

O'Keeffe, G.C., Barker, R.A., and Caldwell, M. A. (2009). Dopaminergic modulation of neurogenesis in the subventricular zone of the adult brain. Cell Cycle 8, 2888-2894.

Omodei, D., Acampora, D., Mancuso, P., Prakash, N., Di Giovannantonio, L. G., Wurst, W., and Simeone, A. (2008). Anterior-posterior graded response to Otx2 controls proliferation and differentiation of dopaminergic progenitors in the ventral mesencephalon. Development 135, 3459-3470.

Ono, Y., Nakatani, T., Sakamoto, Y. Mizuhara, E., Minaki, Y., Kumai, M., Hamaguchi, A., Nishimura, M., Inoue, Y., Hayashi, H., Takahashi, J., and Imai, T. (2007). Differences in neurogenic potential in floor plate cells along an anteroposterior location: midbrain dopaminergic neurons originate from mesencephalic floor plate cells. Development 134, 3213-3225.

Osorio, J., Mueller, T., Retaux, S., Vernier, P., and Wullimann, M. F. (2010). Phylotypic expression of the bHLH genes Neurogenin2, Neurod, and Mashl in the mouse embryonic forebrain. J. Comp. Neurol. 518, 851-871.

Panopoulou, G., and Poustka, A. J. (2005). Timing and mechanism of ancient vertebrate genome duplications - the adventure of a hypothesis. Trends Genet. 21, 559-567.

Parent, A., and Northcutt, R. G. (1982). The monoamine-containing neurons in the brain of the garfish Lepisosteus osseus. Brain Res. Bull. 9, 189-204.

Parsons, S. M. (2000). Transport mechanisms in acetylcholine and monoamine storage. FASEB J. 14, 2423-2434.

Patton, S. J., Luke, G. N., and Holland, P.W. (1998). Complex history of a chromosomal paralogy region: insights from amphioxus aromatic amino acid hydroxylase genes and insulin-related genes. Mol. Biol. Evol. 15, 1373-1380.

Petko, M., and Orosz, V. (1996). Distribution of somatostatin-immunoreactive structures in the central nervous system of the frog, Rana esculenta. J. Hirnforsch. 37, 109-120.
Pierre, J., Mahouche, M., Suderevskaya, E. I., Reperant, J., and Ward, R. (1997). Immunocytochemical localization of dopamine and its synthetic enzymes in the central nervous system of the lamprey Lampetra fluviatilis. J. Comp. Neurol. 380, 119-135.

Postlethwait, J. H., Woods, I. G., NgoHazelett, P., Yan, Y. L., Kelly, P. D. Chu, F., Huang, H., Hill-Force, A., and Talbot, W. S. (2000). Zebrafish comparative genomics and the origins of vertebrate chromosomes. Genome Res. 10, 1890-1902.

Prakash, N., Brodski, C., Naserke, T., Puelles, E., Gogoi, R., Hall, A., Panhuysen, M., Echevarria, D., Sussel, L., Weisenhorn, D. M., Martinez, S., Arenas, E., Simeone, A., and Wurst, W. (2006). A Wnt1-regulated genetic network controls the identity and fate of midbrain dopaminergic progenitors in vivo. Development 133, 89-98.

Prakash, N., and Wurst,W. (2006). Genetic networks controlling the development of midbrain dopaminergic neurons. $J$. Physiol. 575, 403-410.

Pucak, M. L., and Grace, A. A. (1994). Regulation of substantia nigra dopamine neurons. Crit. Rev. Neurobiol. 9, 67-89.

Puelles, E., Annino, A., Tuorto, F., Usiello, A., Acampora, D., Czerny, T., Brodski, C., Ang, S. L., Wurst, W., and Simeone, A. (2004). Otx2 regulates the extent, identity and fate of neuronal progenitor domains in the ventral midbrain. Development 131, 2037-2048.

Puelles, L. (1995). A segmental morphological paradigm for understanding vertebrate forebrains. Brain Behav. Evol. 46, 319-337.

Puelles, L., and Medina, L. (1994). "Development of neurons expressing tyrosine hydroxylase and dopamine in the chicken brain: a comparative segmental analysis," in Phylogeny and Development of Catecholamine Systems in the CNS of Vertebrates, eds W. J. A. J. Smeets and A. Reiner (Cambridge: Cambridge University Press), 21-47.

Puelles, L., and Rubenstein, J. L. (2003). Forebrain gene expression domains and the evolving prosomeric model. Trends Neurosci. 26, 469-476.

Reiner, A. (2002). Functional circuitry of the avian basal ganglia: implications for basal ganglia organization in stem amniotes. Brain Res. Bull. 57, 513-528.

Reiner, A., Karle, E. J., Anderson, K. D., Medina,L.(1994)."Catecholaminergic perikarya and fibers in the avian nervous system," in Phylogeny and Development of Catecholamine Systems in the CNS of Vertebrates, eds W. J. A. J. Smeets and A. Reiner (Cambridge: Cambridge University Press), 135-181. 
Reiner, A., Perkel, D. J., Bruce, L. L., Butler, A. B., Csillag, A., Kuenzel, W., Medina, L., Paxinos, G., Shimizu, T., Striedter, G., Wild, M., Ball, G. F., Durand, S., Gunturkun, O., Lee, D. W., Mello, C. V., Powers, A., White, S. A., Hough, G., Kubikova, L., Smulders, T. V., Wada, K., Dugas-Ford, J., Husband, S., Yamamoto, K., Yu, J., Siang, C., and Jarvis, E. D. (2004). Revised nomenclature for avian telencephalon and some related brainstem nuclei. J. Comp. Neurol. 473, 377-414.

Rey, E., Hernandez-Diaz, F. J., Abreu, P., Alonso, R., and Tabares, L. (2001). Dopamine induces intracellular $\mathrm{Ca} 2+$ signals mediated by alpha1Badrenoceptors in rat pineal cells. Eur. J. Pharmacol. 430, 9-17.

Rink, E., and Wullimann, M. F. (2001). The teleostean (zebrafish) dopaminergic system ascending to the subpallium (striatum) is located in the basal diencephalon (posterior tuberculum). Brain Res. 889, 316-330.

Rose, J., Schiffer, A. M., Dittrich, L. and Güntürkün, O. (2010). The role of dopamine in maintenance and distractability of attention in the "prefrontal cortex" of pigeons. Neuroscience 167, 232-237.

Roubert, C., Sagne, C., Kapsimali, M., Vernier, P., Bourrat, F., and Giros, B. (2001). A Na(+)/Cl(-)-dependent transporter for catecholamines, identified as a norepinephrine transporter, is expressed in the brain of the teleost fish medaka (Oryzias latipes). Mol. Pharmacol. 60, 462-473.

Ruffolo, R. R. Jr., and Morgan, E. L. (1984). Interaction of the novel inotropic agent, ASL-7022, with alpha and beta adrenoceptors in the cardiovascular system of the pithed rat: comparison with dobutamine and dopamine. $J$. Pharmacol. Exp. Ther. 229, 364-371.

Russek-Blum, N., Gutnick, A., NabelRosen, H., Blechman, J., Staudt, N., Dorsky, R. I., Houart, C., and Levkowitz, G. (2008). Dopaminergic neuronal cluster size is determined during early forebrain patterning. Development 135, 3401-3413.

Ryu, S., Holzschuh, J., Mahler, J., and Driever, W. (2006). Genetic analysis of dopaminergic system development in zebrafish. J. Neural Transm. Suppl. 61-66.

Ryu, S., Mahler, J., Acampora, D., Holzschuh, J., Erhardt, S., Omodei, D., Simeone, A., and Driever, W. (2007). Orthopedia homeodomain protein is essential for diencephalic dopaminergic neuron development. Curr. Biol. 17, 873-880.

Saenz-de-Miera, L. E., and Ayala, F. J. (2004). Complex evolution of orthologous and paralogous decarboxylase genes. J. Evol. Biol. 17, 55-66.
Sallinen, V., Sundvik, M., Reenila, I., Peitsaro, N., Khrustalyov, D., Anichtchik, O., Toleikyte, G., Kaslin, J., and Panula, P. (2009). Hyperserotonergic phenotype after monoamine oxidase inhibition in larval zebrafish. J. Neurochem. 109, 403-415.

Sanchez-Camacho, C., Marin, O., Smeets, W. J., Ten Donkelaar, H. J., and Gonzalez, A. (2001). Descending supraspinal pathways in amphibians. II. Distribution and origin of the catecholaminergic innervation of the spinal cord. J. Comp. Neurol. 434, 209-232.

Satir, P. (2000). A comment on the origin of the vertebrate eye. Anat. Rec. 261, 224-227.

Saucedo-Cardenas, O., Quintana-Hau, J. D., Le, W. D., Smidt, M. P., Cox, J. J., De Mayo, F., Burbach, J. P., and Conneely, O.M. (1998). Nurrl is essential for the induction of the dopaminergic phenotype and the survival of ventral mesencephalic late dopaminergic precursor neurons. Proc. Natl. Acad. Sci. U.S.A 95, 4013-4018.

Schweitzer, J., and Driever, W. (2009). "Development of dopamine systems in zebrafish," in Development and Engineering of Dopamine Neurons, eds R. J. Pasterkamp, M. P. Smidt, and J. P. H. Burbach (Austin, TX: Landes BioScience), 1-14.

Sharp, T., Zetterstrom, T., and Ungerstedt, U. (1986). An in vivo study of dopamine release and metabolism in rat brain regions using intracerebral dialysis. J. Neurochem. 47, 113-122.

Shimizu, T., and Hibi, M. (2009). Formation and patterning of the forebrain and olfactory system by zinc-finger genes Fezfl and Fezf2. Dev. Growth Differ. 51, 221-231.

Simon, H., Saueressig, H., Wurst, W., Goulding, M., and O'Leary, D. (2001). Fate of midbrain dopaminergic neurons controlled by the engrailed genes. J. Neurosci. 21, 3126-3134.

Smeets, W. J., and Reiner, A. (1994). "Catecholamines in the CNS of vertebrates: current concepts of evolution and functional significance," in Phylogeny and Development of Catecholamine Systems in the CNS of Vertebrates, eds W. J. A. J. Smeets and A. Reiner (Cambridge: Cambridge University Press), 463-481.

Smeets, W.J.A.J. (1994). “Catecholamines in the CNS of reptiles: structure and functional considerations," in Phylogeny and Development of Catecholamine Systems in the CNS of Vertebrates, eds W. J. A. J. Smeets and A. Reiner (Cambridge: Cambridge University Press), 21-47.

Smeets, W.J.A. J., and González, A. (2000) Catecholamine systems in the brain of vertebrates: new perspectives through a comparative approach. Brain Res. Brain Res. Rev. 33, 308-379.

Smidt, M. P., Asbreuk, C. H., Cox, J. J. Chen, H., Johnson, R. L., and Burbach, J. P. (2000). A second independent pathway for development of mesencephalic dopaminergic neurons requires Lmxlb. Nat. Neurosci. 3, 337-341.

Smidt, M. P., and Burbach, J. P. (2007). How to make a mesodiencephalic dopaminergic neuron. Nat. Rev. Neurosci. 8, 21-32.

Smits, S. M., Ponnio, T., Conneely, O. M. Burbach, J. P., and Smidt, M. P. (2003). Involvement of Nurr1 in specifying the neurotransmitter identity of ventral midbrain dopaminergic neurons. Eur. J. Neurosci. 18, 1731-1738.

Stigloher, C., Ninkovic, J., Laplante, M. Geling, A., Tannhäuser, B., Topp, S. Kikuta, H., Becker, T. S., Houart, C., and Bally-Cuif, L. (2006). Segregation of telencephalic and eye-field identities inside the zebrafish forebrain territory is controlled by Rx3. Development 133, 2925-2935.

Stuesse, S. L., Cruce, W. L. R., and Northcutt, R. G. (1994). "Localization of catecholamines in the brains of Chondrichthyes (cartilaginous fishes)," in Phylogeny and Development of Catecholamine Systems in the CNS of Vertebrates, eds W. J. A. J. Smeets and A. Reiner (Cambridge: Cambridge University Press), 21-47.

Sugamori, K. S., Demchyshyn, L. L. Chung, M., and Niznik, H. B. (1994) D1A, D1B, and D1C dopamine receptors from Xenopus laevis. Proc. Natl. Acad. Sci. U.S.A. 91, 10536-10540.

Sulzer, D., and Edwards, R. H. (2005) Antidepressants and the monoamine masquerade. Neuron 46, 1-2.

Szarek, E., Cheah, P. S., Schwartz, J., and Thomas, P. (2010). Molecular genetics of the developing neuroendocrine hypothalamus. Mol. Cell. Endocrinol. 323, 115-123.

Tang, H. (2009). Regulation and function of the melanization reaction in Drosophila. Fly (Austin) 3, 105-111.

Tay, T. L., Ronneberger, O., Ryu, S. Nitschke, R., and Driever, W. (2011). Comprehensive catecholaminergic projectome analysis reveals singleneuron integration of zebrafish ascending and descending dopaminergic systems. Nat. Commun. 2, 171.

Teigen, K., Dao, K. K., McKinney, J. A., Gorren, A. C., Mayer, B., Froystein N. A., Haavik, J., and Martinez, A. (2004). Tetrahydrobiopterin binding to aromatic amino acid hydroxylases. Ligand recognition and specificity. $J$. Med. Chem. 47, 5962-5971.

Thiery, J. C., Chemineau, P., Hernandez, X., Migaud, M., and Malpaux, B.
(2002). Neuroendocrine interactions and seasonality. Domest. Anim. Endocrinol. 23, 87-100.

Tillet, Y. (1994). "Catecholaminergic neuronal systems in the diencephalon of mammals," in Phylogeny and Development of Catecholamine Systems in the CNS of Vertebrates, eds W. J. A. J. Smeets and A. Reiner (Cambridge: Cambridge University Press), 207-246.

Torres, G. E., Gainetdinov, R. R., and Caron, M. G. (2003). Plasma membrane monoamine transporters: structure, regulation and function. Nat. Rev. Neurosci. 4, 13-25.

Valentini, V., Frau, R., and Di Chiara, G. (2004). Noradrenaline transporter blockers raise extracellular dopamine in medial prefrontal but not parietal and occipital cortex: differences with mianserin and clozapine. $J$. Neurochem. 88, 917-927.

Vandepoele, K., De Vos, W., Taylor, J. S. Meyer, A., and Van de Peer, Y. (2004). Major events in the genome evolution of vertebrates: paranome age and size differ considerably between ray-finned fishes and land vertebrates. Proc. Natl. Acad. Sci. U.S.A. 101, 1638-1643.

Verney, C., Zecevic, N., and Puelles, L. (2001). Structure of longitudinal brain zones that provide the origin for the substantia nigra and ventral tegmental area in human embryos, as revealed by cytoarchitecture and tyrosine hydroxylase, calretinin, calbindin, and GABA immunoreactions. J. Comp. Neurol. 429, 22-44.

Vernier, P., Moret, F., Callier, S., Snapyan, M., Wersinger, C., and Sidhu, A. (2004) The degeneration of dopamine neurons in Parkinson's disease: insights from embryology and evolution of the mesostriatocortical system. Ann. N. Y. Acad. Sci. 1035, 231-249.

Vernier, P., and Wullimann, M. F. (2009). "Evolution of the posterior tuberculum and preglomerular nuclear complex," in Encyclopedia of Neurosciences Part 5, eds M. D. Binder, N. Hirokawa, and U. Windhorst (Berlin: SpringerVerlag), 1404-1413.

Vieira, C., Pombero, A., Garcia-Lopez, R., Gimeno, L., Echevarria, D., and Martinez,S. (2010). Molecular mechanisms controlling brain development: an overview of neuroepithelial secondary organizers. Int. J. Dev. Biol. 54, 7-20.

Vigh, B., Manzano e Silva, M. J., Frank, C. L., Vincze, C., Czirok, S. J., Szabó, A., Lukáts, A., and Szél, A. (2004). The system of cerebrospinal fluid-contacting neurons. Its supposed role in the nonsynaptic signal transmission of the brain. Histol. Histopathol. 19, 607-628.

Vigh, B., Manzano, M. J., Zádori,A., Frank C. L., Lukáts, A., Röhlich, P., Szél, A., and Dávid, C. (2002). Nonvisual 
photoreceptors of the deep brain, pineal organs and retina. Histol. Histopathol. 17, 555-590.

Vigh-Teichmann, I., and Vigh, B. (1983). The system of cerebrospinal fluid-contacting neurons. Arch. Histol. Jpn. 46, 427-468.

Vitalis, T., Cases, O., Engelkamp, D., Verney, C., and Price, D. J. (2000). Defect of tyrosine hydroxylase-immunoreactive neurons in the brains of mice lacking the transcription factor Pax6. J. Neurosci. 20, 6501-6516.

Vizi, E. S., Zsilla, G., Caron, M. G., and Kiss, J. P. (2004). Uptake and release of norepinephrine by serotonergic terminals in norepinephrine transporter knock-out mice: implications for the action of selective serotonin reuptake inhibitors. J. Neurosci. 24, 7888-7894.

Volff, J.N. (2005). Genome evolution and biodiversity in teleost fish. Heredity 94 , 280-294.

Wada, H., Saiga, H., Satoh, N., and Holland, P. W. (1998). Tripartite organization of the ancestral chordate brain and the antiquity of placodes: insights from ascidian Pax-2/5/8, Hox and Otx genes. Development 125 , 1113-1122.

Walls, G. L. (1942). The Vertebrate Eye and its Adaptive Radiation. New York: Hafner, 785.

Wang, S., and Turner, E. E. (2010). Expression of dopamine pathway genes in the midbrain is independent of known ETS transcription factor activity. J. Neurosci. 30, 9224-9227.

Wang, W., and Lufkin, T. (2000). The murine Otp homeobox gene plays an essential role in the specification of neuronal cell lineages in the developing hypothalamus. Dev. Biol. 227, 432-449.

Weihe, E., Depboylu, C., Schutz, B., Schafer, M. K., and Eiden, L.E. (2006). Three types of tyrosine hydroxylasepositive CNS neurons distinguished by dopa decarboxylase and VMAT2 co-expression. Cell. Mol. Neurobiol. 26, 659-678.

Weihe, E., and Eiden, L. E. (2000). Chemical neuroanatomy of the vesicular amine transporters. FASEB J. 14, 2435-2449.

Westlund, K. N., Denney, R. M., Kochersperger, L. M., Rose, R. M., and Abell,C.W. (1985). Distinct monoamine oxidase $\mathrm{A}$ and $\mathrm{B}$ populations in primate brain. Science 230, 181-183.

Willoughby, J., Glover, V., and Sandler, M. (1988). Histochemical localisation of monoamine oxidase $\mathrm{A}$ and $\mathrm{B}$ in rat brain. J. Neural Transm. 74, 29-42.

Wilson, S. W., and Houart, C. (2004). Early steps in the development of the forebrain. Dev. Cell 6, 167-181.

Wise, R. A. (2009). Roles for nigrostriatal - not just mesocorticolimbic dopamine in reward and addiction. Trends Neurosci. 32, 517-524.
Wullimann, M. F., and Rink, E. (2001). Detailed immunohistology of Pax6 protein and tyrosine hydroxylase in the early zebrafish brain suggests role of Pax6 gene in development of dopaminergic diencephalic neurons. Brain Res. Dev. Brain Res. 131, 173-191.

Xhaard, H., Rantanen, V. V., Nyronen, T., and Johnson, M. S. (2006). Molecular evolution of adrenoceptors and dopamine receptors: implications for the binding of catecholamines. J. Med. Chem. 49, 1706-1719.

Yamamoto, K., Ruuskanen, J. O. Wullimann, M. F., and Vernier, P. (2010). Two tyrosine hydroxylase genes in vertebrates: comparative distribution with other monoaminergic markers in the zebrafish brain. Mol. Cell Neurosci. 43, 394-402.

Yamamoto, K., Ruuskanen, J. O., Wullimann, M. F., and Vernier, P. (2011). Differential expression of dopamine cells markers in the adult zebrafish forebrain. J. Comp. Neurol. 519, 576-598.

Zetterström, R. Zetterström, R. H., Solomin, L., Jansson, L., Hoffer, B. J., Olson, L., and Perlmann, T. (1997). Dopamine neuron agenesis in Nurr 1deficient mice. Science 276, 248-250.

Zhang, W., Klimek, V., Farley, J. T. Zhu, M. Y., and Ordway, G. A. (1999). Alpha2C adrenoceptors inhibit adenylyl cyclase in mouse striatum: potential activation by dopamine. J. Pharmacol. Exp. Ther. 289, 1286-1292.

Zhou, F. M., Liang, Y., Salas, R., Zhang, L., De Biasi, M., and Dani, J. A. (2005). Corelease of dopamine and serotonin from striatal dopamine terminals. Neuron 46, 65-74.

Zohar, Y., Munoz-Cueto, J. A., Elizur, A., and Kah, O. (2010). Neuroendocrinology of reproduction in teleost fish. Gen. Comp. Endocrinol. $165,438-455$.

Conflict of Interest Statement: The authors declare that the research was conducted in the absence of any commercial or financial relationships that could be construed as a potential conflict of interest.

Received: 31 December 2010; paperpending published: 24 January 2011; accepted: 15 March 2011; published online: 29 March 2011.

Citation: Yamamoto $K$ and Vernier $P$ (2011) The evolution of dopamine systems in chordates. Front. Neuroanat. 5:21. doi: 10.3389/fnana.2011.00021

Copyright (c) 2011 Yamamoto and Vernier. This is an open-access article subject to an exclusive license agreement between the authors and Frontiers Media $S A$, which permits unrestricted use, distribution, and reproduction in any medium, provided the original authors and source are credited. 